(C) 2021, The Authors. Published by Elsevier Inc. and Fass Inc. on behalf of the American Dairy Science Association ${ }^{\circledR}$. This is an open access article under the CC BY-NC-ND license (http://creativecommons.org/licenses/by-nc-nd/4.0/).

\title{
Relative virulence of Staphylococcus aureus bovine mastitis strains representing the main Canadian spa types and clonal complexes as determined using in vitro and in vivo mastitis models
}

\author{
Elodie Demontier, ${ }^{1}$ (C) Alexis Dubé-Duquette, ${ }^{1}$ Eric Brouillette, ${ }^{1}$ Audrey Larose, ${ }^{1}$ Céline Ster, ${ }^{1 *}$ (1) \\ Jean-François Lucier, ${ }^{1}$ Sébastien Rodrigue, ${ }^{1}$ Soyoun Park, ${ }^{2}$ Dongyun Jung, ${ }^{2}$ Janina Ruffini, ${ }^{2}$ \\ Jennifer Ronholm, ${ }^{2} \odot$ Simon Dufour, ${ }^{3} \odot$ Jean-Philippe Roy, ${ }^{3} \odot$ Sheela Ramanathan, ${ }^{4}$ and François Malouin ${ }^{1} \dagger \odot$ \\ ${ }^{1}$ Département de Biologie, Faculté des Sciences, Université de Sherbrooke, Sherbrooke, QC, J1K 2R1, Canada \\ ${ }^{2}$ Faculty of agricultural and environmental sciences, Macdonald campus, McGill University, Ste-Anne-de-Bellevue, QC, H9X 3V9, Canada. \\ ${ }^{3}$ Département de pathologie et microbiologie and Département de sciences cliniques, Faculté de médecine vétérinaire, Université de Montréal, \\ St-Hyacinthe, QC, J2S 2M2, Canada \\ ${ }^{4}$ Département d'immunologie et de biologie cellulaire, Faculté de médecine et des sciences de la santé, Université de Sherbrooke, Sherbrooke, \\ QC, J1H 5N4, Canada
}

\section{ABSTRACT}

Staphylococcus aureus is one of the main pathogens leading to both clinical and subclinical bovine mastitis in dairy cattle. Prediction of disease evolution based on the characteristics of Staph. aureus isolates that cause intramammary infections and understanding the host-pathogen interactions may improve management of mastitis in dairy herds. For this study, several strains were selected from each of the 6 major Canadian spa types associated with mastitis (t267, t359, t529, t605, t2445, and t13401). Adherence to host cells and intracellular persistence of these strains were studied using a bovine mammary gland epithelial cell line (MACT). Additionally, relative virulence and host response (cytokines production) were also studied in vivo using a mouse model of mastitis. Whole-genome sequencing was performed on all strains and associations between clonal complex, sequence type, and presence of certain virulence factors were also investigated. Results show that spa type t2445 was correlated with persistence in MAC-T cells. Strains from spa t359 and t529 showed better ability to colonize mouse mammary glands. The exception was strain sa3154 (spa t529), which showed less colonization of glands compared with other t359 and t529 strains but possessed the highest number of superantigen genes including tst. All strains possessed hemolysins, but spa types t529 and t2445 showed the largest diameter of $\beta$-hemolysis on blood agar plates. Although several spa types possessed 2 or 3 serine-

Received November 12, 2020.

Accepted July 7, 2021.

*Current address: Sherbrooke Research and Development Centre, Agriculture and Agri-Food Canada, Sherbrooke, QC, J1M 0C8, Canada.

†Corresponding author: francois.malouin@usherbrooke.ca aspartate rich proteins (Sdr) believed to be involved in many pathogenic processes, most t529 strains expressed only an allelic variant of $s d r E$. The spa types t605 (positive for the biofilm associated protein gene; $b a p+$ ) and t13401 (bap-), that produced the largest amounts of biofilm in vitro, were the least virulent in vivo. Finally, strains from spa type t529 (ST151) elicited a cytokine expression profile (TNF- $\alpha$, IL-1 $\beta$ and IL-12) that suggests a potential for severe inflammation. This study suggests that determination of the spa type may help predict the severity of the disease and the ability of the immune system to eliminate intramammary infections caused by Staph. aureus.

Key words: Staphylococcus aureus, spa type, bovine mastitis, intramammary infection, host immune response

\section{INTRODUCTION}

Bovine mastitis is an inflammation of the mammary gland most often caused by a bacterial IMI. The disease may be asymptomatic or symptomatic (subclinical or clinical mastitis), persistent (chronic) or nonpersistent. Bovine mastitis places a considerable economic burden on the world dairy industry. The cost is estimated at $660 \mathrm{CAD}$ (US\$520 at time of writing) per lactating cow per year for Canadian dairy farms (Aghamohammadi et al., 2018). In Canada, Staphylococcus aureus is the most prevalent pathogen recovered from clinical mastitis and the second most frequently isolated bacteria, after nonaureus staphylococci, from apparently healthy cows (Reyher et al., 2011). Chronic Staph. aureus IMI may last several weeks during lactation (Pichette-Jolette et al., 2019), as pathogen clearance by the host immune system is difficult (Côté-Gravel and Malouin, 2019) and antibiotic treatment is minimally effective (Ster et al., 
2017) due to virulence factors promoting cell invasion (Proctor et al., 2006) and biofilm formation (Melchior et al., 2007; Jacques et al., 2010).

Biofilm production by Staph. aureus also influences manifestations of the disease. Biofilms are extracellular matrices that minimize antibodies opsonization and phagocytosis. Bacteria within biofilms are also less susceptible to antibiotics (Jacques et al., 2010). Staphylococcus aureus can produce biofilms of various kinds. The polysaccharide intercellular adhesin found in biofilms is primarily composed of exopolysaccharides [poly- $\beta(1-6)-N$-acetylglucosamine] synthetized by the icaABDC operon, whereas the bap gene can form a protein-based biofilm (biofilm associated protein; Snel et al., 2015; Taglialegna et al., 2016). The quorum-sensing system Agr is one of the most significant regulatory mechanisms controlling biofilm formation in Staph. aureus (Arciola et al., 2015). Low activation of the Agr system results in high biofilm production (Otto, 2013).

During the establishment of the infection, Staph. aureus can utilize one or more of its microbial surface components recognizing adhesive matrix molecules (MSCRAMM) to interact with and colonize mammalian hosts. Serine-aspartate rich (Sdr) proteins are virulence factors that are part of the MSCRAMM family in Staph. aureus (Foster et al., 2014; Foster, 2019), and their implication in biofilm formation, adhesion to host molecules and immune evasion mechanisms have been previously described (Barbu et al.., 2014; Sharp et al.., 2012). Capsular polysaccharides (CPS) produced at the surface of bacteria and the CPS types may influence virulence and host defenses (O'Riordan and Lee, 2004). The CPS types (mainly CP5 or CP8) or the level of capsule expression are among the proposed characteristics enabling Staph. aureus to cause lasting infections.

During colonization of the mammary gland, Staph. aureus can produce several virulence factors to sustain infection and promote its survival in the host. These virulence factors are generally associated with damage to the mammary gland epithelium and local inflammation and are also associated with clinical signs (Rainard et al., 2018). In addition, enterotoxins, enterotoxins-like and TSST-1 (coded by the tst gene) are superantigens (SAg) which, when expressed by the bacterium, may stimulate one or more $\mathrm{T}$ lymphocyte subfamilies. This results in an uncontrolled release of pro-inflammatory mediators that greatly affects efficacy of the immune response (Wilson et al., 2018).

Cytokines and chemokines are soluble proteins or glycoproteins secreted by a wide variety of cells such as immune (e.g., neutrophils) and epithelial cells (Oviedo-Boyso et al., 2007). The Holstein breed, which is more susceptible to infections, is more likely to develop chronic inflammation due to a high production of pro-inflammatory cytokines such as IL-1 $\beta$ and tumor necrosis factor (TNF)- $\alpha$ compared with other breeds such as the Rendena breed (Curone et al., 2018). These 2 cytokines are often associated with IMI caused by Staph. aureus (Oviedo-Boyso et al., 2007; Bannerman et al., 2004, 2008; Bannerman, 2009). Two other cytokines that have been associated with IMIs caused by Staph. aureus are pro-inflammatory IL-12 that induces IFN- $\gamma$ (Mühl and Pfeilschifter, 2003) involved in the activation of neutrophils and macrophages (Bannerman et al., 2004, 2008; Bannerman, 2009), and that promotes the Th1 type cell-mediated immune response (Trinchieri, 1997; Bannerman et al., 2008). Concentrations of certain growth factors normally present in a healthy gland, such as transforming growth factor (TGF)- $\alpha$ and TGF- $\beta 1$, which are respectively pro- and anti-inflammatory, are increased in milk during an IMI caused by Staph. aureus (Bannerman et al., 2008).

Studies on the correlation of virulence factors of bovine isolates to various disease manifestations have met with incomplete success (Veh et al., 2015; Pichette-Jolette et al., 2019; Hoekstra et al., 2020; Naushad et al., 2020). There are many reasons for this partial correlation. On the one hand, not all Staph. aureus strains possess all virulence factors and if several are present, they may act synergistically. On the other hand, because it is difficult to control the homogeneity of the cow population, and because the immune response of each cow in observational studies varies greatly according to parity, DIM, and genetic background (Bannerman et al., 2008; Canning et al., 2017; Ruiz et al., 2017; Curone et al., 2018), any association between bacterial virulence and clinical outcome in cows is very difficult to establish. It would be prohibitively expensive to conduct an experiment in which Staph. aureus lineages with or without particular virulence factors were randomly assigned to a standardized cow population to assess clinical outcomes. This is why the present study aimed to compare virulence-associated phenotypes of Staph. aureus strains most commonly recovered from quarter milk samples using assays and conditions that could be monitored and controlled in the laboratory. The phenotypes studied included adhesion to and persistence within bovine mammary gland epithelial cells in vitro, whereas the ability to colonize the mammary gland and the host cytokine expression response to Staph. aureus colonization were studied in a mouse mastitis model. Also, because Staph. aureus strains are grouped into specific clonal lineages each possessing specific sets of virulence factors and remarkably similar genomes because of a highly developed restriction-modification system that 
prevents horizontal gene transfer among lineages (Park et al., 2020), we used spa typing to represent the different types of strains to be compared in this study. The spa gene is indeed one of the most useful single genetic markers for distinguishing Staph. aureus lineages (Aires-de-Sousa et al., 2006; Rodriguez et al., 2015). Results show that determining the spa type of mastitis isolates may help predict disease outcome in cows.

\section{MATERIALS AND METHODS}

\section{Bacterial Strains}

Twenty-three Staph. aureus strains from quarter milk samples partly characterized by Pichette-Jolette et al. (2019) were used in this study. The strains were obtained from the Mastitis Pathogen Culture Collection of the Canadian Bovine Mastitis and Milk Quality Research Network (Faculté de Médecine Vétérinaire, Université de Montréal, St-Hyacinthe, QC, Canada). These strains were collected from 91 Canadian herds, participating in the National Cohort of Dairy Farms located in the Atlantic Provinces, Quebec, Ontario, and Western Canada, and followed for 2 years (2007 and 2008). All Staph. aureus strains were from quarter milk samples with at least one colony detected in a $10-\mu \mathrm{L}$ sample $(100 \mathrm{cfu} / \mathrm{mL})$. The Staph. aureus species were confirmed by a positive catalase test, hemolysis on blood agar, and positive nuclease and coagulase tests. All strains collected were archived and a barcode was assigned in the database with all related information at the farm, cow, and quarter level (Reyher et al., 2011).

The 23 strains were chosen to represent the most prevalent spa types found in Canadian dairy cattle (Veh et al., 2015; Pichette-Jolette et al., 2019). The 6 most prevalent spa types were t529 $(\mathrm{n}=115), \mathrm{t} 267$ (n $=67), \mathrm{t} 359(\mathrm{n}=36), \mathrm{t} 605(\mathrm{n}=18), \mathrm{t} 2445(\mathrm{n}=11)$, and t13401 ( $\mathrm{n}=10)$ (Pichette-Jolette et al., 2019). To avoid picking nonrepresentative outliers, we used the already available data on biofilm production as guidance for strain selection (Pichette-Jolette et al., 2019). We made sure the in vitro biofilm production of selected strains was within the interquartile range of each spa type population. Hence, within this interquartile range, 3 strains were randomly picked for spa types t267, t359, t605, and t2545. On the other hand, for spa type t529, which was overrepresented in Canadian bovine strains (collection of $\mathrm{n}=115$ ), we randomly picked 6 tst-negative and 1 tst-positive strains (Table 1). Although only $8 \%$ of the 115 t529 isolates were positive for the tst gene, we wanted to make sure that at least one strain possessing such a superantigen gene was included in the study. Noteworthy, spa types t605 and t2445 were described as strong and weak biofilm producers, respectively (Pichette-Jolette et al., 2019). Strains from spa type t13401 were also strong biofilm producers but because they differed phenotypically and genotypically from the other 9 strains of the clonal complex (CC) CC97 based on biofilm production and on the presence/absence of the lukM gene, respectively, (Table 1), 4 strains (instead of 3) were chosen and studied for that group. Clonal complex CC97 is among the most widespread CC in Europe (Hoekstra et al., 2020), and strains producing the LukMF' leukocidin (encoded by $l u k M F$ ) have been associated with bovine lineages of Staph. aureus (Vrieling et al., 2016; Hoekstra et al., 2018).

\section{Whole-Genome Sequencing, Assembly, and Annotation}

Staphylococcus aureus strains were inoculated in $3 \mathrm{~mL}$ of brain heart infusion medium (Becton Dickinson). The GenElute Bacterial Genomic DNA Kit (Sigma-Aldrich) was used to extract bacterial DNA as described before (Pichette-Jolette et al., 2019). Illumina sequencing libraries were then prepared from $100 \mathrm{ng}$ of DNA using the QIAGEN QIAseq FX DNA Library Kit for Illumina instrument according to the manufacturer (QIAGEN). All purifications were made on double solid phase reversible immobilization using carboxyl-coated magnetic beads with an adjusted ratio. Desired fragment sizes were between $600 \mathrm{bp}$ and $800 \mathrm{bp}$ and obtained by treatment with the doublestranded DNA Shearase enzyme (Zymo Research) according to the manufacturer. Libraries were prepared according to Baby et al. (2018) and validated using a 2100 Bioanalyser (Agilent Technologies). A PicoGreen fluorometric assay was used to quantify gDNA before pooling libraries. Sequencing was performed on an Illumina HiSeq 2000 sequencing system at the Plateau de Biologie Moléculaire et Génomique Fonctionnelle of the Institut de Recherche Cliniques de Montréal (Montreal, QC, Canada). Samples were multiplexed in a single sequencing lane, and approximately 1 million to 2 million paired-end reads of $50 \mathrm{bp}$ were obtained for each library.

The resulting reads were de novo assembled using a custom assembly pipeline based on the Roche Newbler Assembler (version 2.9, http://sequencing.roche .com). Briefly, sequencing reads were trimmed for adaptor sequences and base call quality established using Trimmomatic v0.36 LEADING:20 TRAILING:20 SLIDINGWINDOW:4:20 MINLEN:36 (Bolger et al., 2014). Trimmed reads were then de novo assembled and in parallel assembled using staph_aureus_RF122 
Demontier et al.: RELATIVE VIRULENCE OF BOVINE STAPHYLOCOCCUS AUREUS

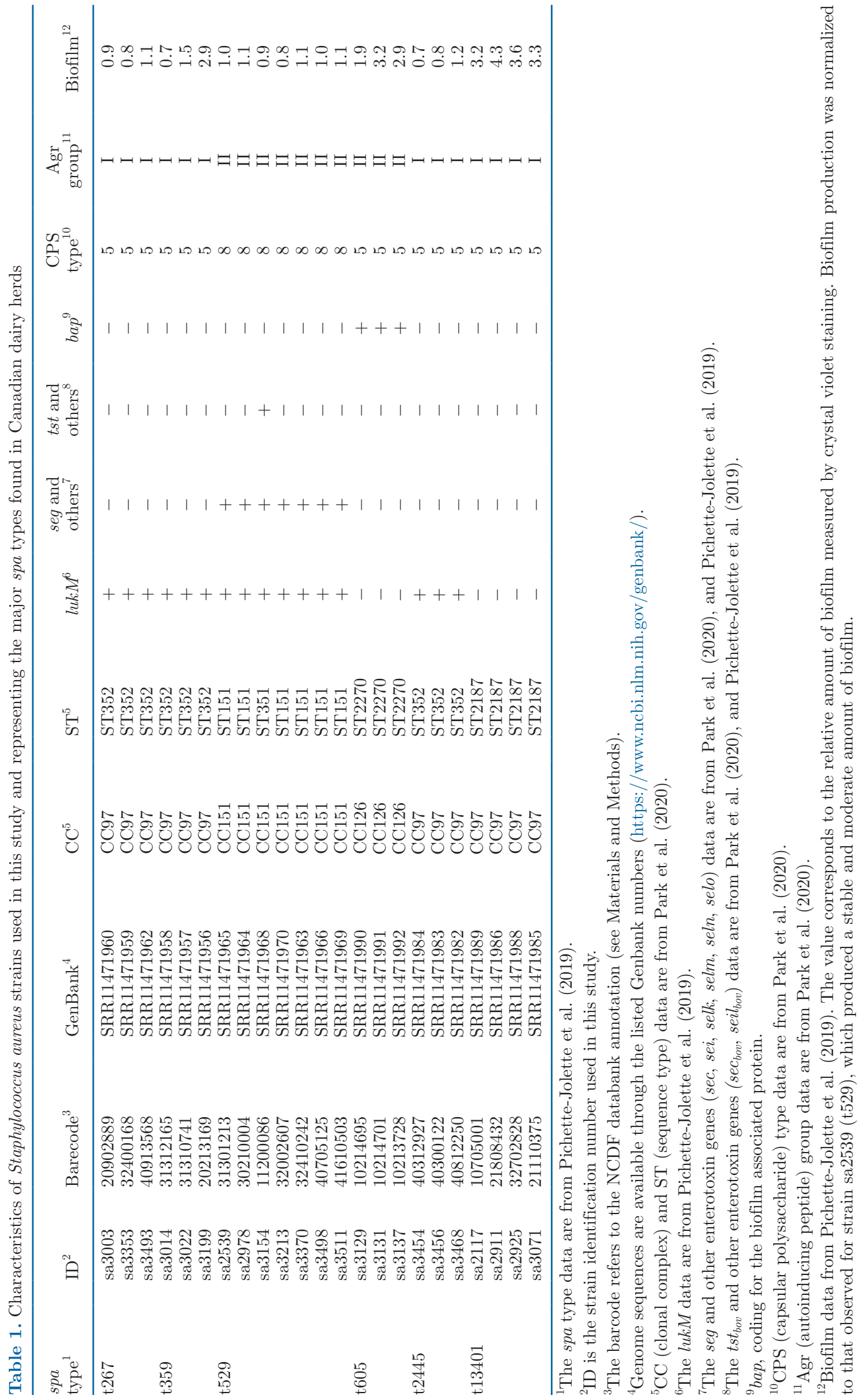


(NC_007622.1) as the reference. Both assembly predictions were then combined using a custom method in which all reads and predicted de novo and reference based contigs were reassembled using the Roche Newbler Assembler (version 2.9). Assembled contigs were annotated using GeneMarks version 4.28 (Besemer et al., 2001).

Blast (version ncbi-blast 2.7.1+; https://blast.ncbi .nlm.nih.gov/Blast.cgi) was done against the UniProt Staph. aureus proteome (https://www.uniprot.org/ uniprot/?query = taxonomy:1280) to identify unique genes and family genes. Core genome was filtered with $>80 \%$ coverage to highlight unique genes for each spa type and each strain. Filtering was done according to the protein sequence of genes (around 3,650 proteins annotated). The multilocus sequence typing was done using Simulate PCR (Gardner and Slezak, 2014) to obtain sequence of the 7 Staph. aureus house-keeping gene $(\operatorname{arc} C$, aroE, glpF, gmk, pta, tpi, and yqi). Their sequences were submitted on PubMLST (https:// pubmlst.org/saureus/) to obtain allelic profiles of genes and to determine the sequence type (ST) of Staph. aureus strains.

To examine strain similarities, a phylogenetic tree and heatmap representation of gene compositions for the 23 Staph. aureus genomes were created. Genes were predicted by Roary (version 3.13.0) using Prokka version 1.14.0 (https://sanger-pathogens.github.io/ Roary/). A total of 3,759 genes were annotated using this pipeline. A total of 2,385 core genes were identified by Roary. A heatmap was generated, using $\mathrm{R}$ v3.6.3 (https://r-project.org) and the gplots package, using the absence or presence matrix of genes produced by Roary. Staph. aureus strains were clustered (complete method) by gene presence and absence using Manhattan distance.

\section{Hemolysis Assay}

Hemolysis by Staph. aureus strains was visualized as previously described (Herbert et al., 2010; Mitchell et al., 2013). Hemolysis was measured because production of the $\alpha$-toxin (Hla) can affect the duration of intracellular persistence by causing cell lysis, which can lead to tissue damage and inflammation (Soe et al., 2021), affecting the phenotypes observed in subsequent assays. Briefly, bacterial suspensions were adjusted to a 0.5 McFarland turbidity standard and were spotted on sheep blood agar plate (Oxoid Microbiology Products). Plates were incubated for $24 \mathrm{~h}$ at $35^{\circ} \mathrm{C}$. After incubation, plates were transferred to $4^{\circ} \mathrm{C}$ for an additional $24 \mathrm{~h}$. Zone diameters (3 replicates per strain) of $\beta$-hemolysis were measured.

\section{Staph. aureus Cellular Adherence and Intracellular Persistence}

A bovine mammary epithelial cell line (MAC-T cells) was used to measure cellular invasion (Moisan et al., 2006). The MAC-T cells were maintained in Dulbecco's modified Eagle medium (Wisent) supplemented with $10 \%$ heat-inactivated fetal bovine serum, $1 \times$ sodium pyruvate (Wisent), $1 \times$ antibiotic and antifungal solution (Wisent), $5 \mu \mathrm{g} / \mathrm{mL}$ insulin (Roche Diagnostics Inc.) and $1 \mu \mathrm{g} / \mathrm{mL}$ hydrocortisone (Sigma). Cells were incubated at $37^{\circ} \mathrm{C}$ with $5 \% \mathrm{CO}_{2}$.

The assay was performed as previously described (Côté-Gravel et al., 2016) with minor modifications. Briefly, $48 \mathrm{~h}$ before inoculation, $\sim 2 \times 10^{5}$ cells $/ \mathrm{mL}$ were added in treated Cell-BIND 24-wells plate (Corning) to obtain a minimum of $50 \%$ confluence the next day. The growth medium was replaced by the invasion medium (IM), a growth medium without antibiotics containing 1\% heat-inactivated fetal bovine serum, 20 to $24 \mathrm{~h}$ prior inoculation. Twenty-four well plates were incubated at $37^{\circ} \mathrm{C}$ with $5 \% \mathrm{CO}_{2}$ until $100 \%$ confluence (monolayer cells). Before cell infection, an overnight culture of the test bacterium was diluted 1:20 in fresh tryptic soy broth medium and grown under agitation to mid-logarithmic growth phase, then washed twice with PBS and diluted in IM to obtain a multiplicity of infection of 50 corresponding to $\sim 2 \times 10^{7}$ bacteria. Infected monolayers were incubated at $37^{\circ} \mathrm{C}$ with $5 \%$ $\mathrm{CO}_{2}$. Bacterial adherence to cells was measured after 30 min of incubation. Cells were then washed 3 times with Dulbecco's PBS (D-PBS) to remove unbound bacteria and were suspended by using trypsin and lysed with $0.05 \%$ Triton X-100. Bacterial cfu was determined by serial dilution on trypticase soy agar (TSA) plates.

Intracellular persistence of bacterial strains was evaluated $20 \mathrm{~h}$ postinfection. After $3 \mathrm{~h}$ of invasion time, monolayers were washed with Dulbecco's modified Eagle medium and incubated $17 \mathrm{~h}$ in IM supplemented with $20 \mu \mathrm{g} / \mathrm{mL}$ lysostaphin (Moisan et al., 2006; Tuchscherr et al., 2010) and $50 \mu \mathrm{g} / \mathrm{mL}$ gentamicin to kill extracellular bacteria. After $20 \mathrm{~h}$ of infection, cells were washed 3 times with D-PBS, and cells were detached from the plate using trypsin and lysed with $0.05 \%$ Triton X-100. Bacterial cfu was determined by serial dilution on TSA plates.

A correction was applied on the measured $\log _{10} \mathrm{cfu} /$ wells to account for MAC-T cell mortality. The MAC-T cell viability was assessed by the reduction of 3-[4,5-dimethylthiazol-2-yl]-2,5 diphenyl tetrazolium bromide (MTT) into insoluble formazan crystals by mitochondria (as described below). Results were expressed using the following formula: 


\author{
$\log _{10}$ bacterial cfu/wells / \\ (Absorbance of MAC-T cells [MTT assay] \\ - Absorbance of bacterial background [MTT assay]),
}

where the bacterial background was the absorbance (MTT assay) of infected cells that were treated with $0.05 \%$ Triton X-100 for 10 min before MTT addition (i.e., the absorbance only due to bacteria).

\section{Staph. aureus Cytotoxicity Assay}

The cytotoxicity of Staph. aureus strains for MAC-T was measured by the MTT assay. The assay was performed as described by Kubica et al. (2008) and CôtéGravel et al. (2016) with minor modifications. Briefly, Staph. aureus infection of MAC-T cells was achieved as described above for the cell invasion assay, without inducing lysis of cells after $30 \mathrm{~min}$ or $20 \mathrm{~h}$ of infection. After each infection time (30 min and $20 \mathrm{~h}$ ), cells were washed as described before and then incubated $2 \mathrm{~h}$ with $100 \mu \mathrm{L}$ of MTT reagent ( $5 \mathrm{mg} / \mathrm{mL}$; Sigma) in D-PBS at $37^{\circ} \mathrm{C}$. Then, cells were lysed, and formazan crystals were solubilized overnight by using an acidic solvent solution of $16 \%$ SDS and 40\% DMF, pH 4.7. Each well was read using an Epoch microplate reader (Biotek Instrument Inc.) at a wavelength of $570 \mathrm{~nm}$. All measurements were performed in duplicate, and 2 controls were included in each plate: a high cell viability control (cells cultured without bacteria) and a lysed, infected cells control (bacterial background control) where infected cells were treated with $0.05 \%$ Triton X-100 for 10 min before MTT addition. The level of metabolic activity was calculated using the following formula:

[(Absorbance of infected cells

- Absorbance of bacterial background)/

High cell viability] $\times 100$.

\section{Mouse Intramammary Infection Model}

The animal experiments were conducted following the guidelines of the Canadian Council on Animal Care and the institutional ethics committee on animal experimentation of Université de Sherbrooke. The institutional ethics committee on animal experimentation of the Faculté des Sciences of Université de Sherbrooke specifically approved the murine mastitis model and the present study protocol (2017-1966 FM2017-01B).

Intramammary infections were performed as described in Brouillette et al. (2004). Briefly, the 12- to 14-d offspring were removed $1 \mathrm{~h}$ before the infection of lactating CD-1 mice (Charles River Laboratories, QC, Canada). Mice were anesthetized with ketamine and xylazine at 83 and $13 \mathrm{mg} / \mathrm{kg}$ of BW, respectively, and 2 mammary glands, right (R4) and left (L4), were inoculated under a binocular. Each mammary duct was exposed by a small cut before injection of $100 \mu \mathrm{L}$ of the tested bacterial suspension $\left(10^{3} \mathrm{cfu} / \mathrm{mL}\right)$ in endotoxinfree D-PBS. Five to 6 glands were infected per test strain. Mammary glands were removed aseptically at $10 \mathrm{~h}$ or $20 \mathrm{~h}$ after infection, depending on the experiment (specified in the figure legends). Glands were easily detached from the skin using small forceps and were completely removed without any contamination from surrounding tissues. Each gland, which holds in one piece, was weighed and inspected for inflammation and redness. Glands were then homogenized in 50 $\mathrm{m} M$ potassium phosphate buffer $\mathrm{pH}$ 6. A fraction was kept aside for the myeloperoxidase (MPO) assay (see below). A $10 \times$ saline solution was diluted 1:10 in the remaining gland homogenate to determine the bacterial load and for detection of cytokines and chemokines. The bacterial load (cfu) was evaluated by serial dilution in PBS and plating on TSA. The cytokine and chemokine assays are described below.

\section{MPO Assay}

Neutrophil recruitment in mammary tissues was measured by quantification of the MPO enzyme activity, which served as an indicator of inflammation, as previously described (Kubica et al., 2008; Côté-Gravel et al., 2016). Briefly, $4 \times$ cetrimonium bromide buffer was added to a $500-\mu \mathrm{L}$ fraction of mammary gland homogenate at a dilution of 1:4. Samples were vortexed for $30 \mathrm{~s}$ and sonicated for $2 \mathrm{~min}$ in a sonication bath. Then, a freeze-thaw step in liquid azote was applied on samples. Samples were centrifuged at $4^{\circ} \mathrm{C}$ for $15 \mathrm{~min}$ in $2000 \times g$. Those supernatants were further centrifuged at $4^{\circ} \mathrm{C}$ for $15 \mathrm{~min}$ at $15,000 \times g$ and aliquoted and stored at $-80^{\circ} \mathrm{C}$ before performing the MPO assays.

In 96-well plates, $10 \mu \mathrm{L}$ of each mammary gland extract in $50 \mathrm{~m} M$ cetrimonium bromide $(1 \times)$ phosphate buffer $50 \mathrm{mM}$, pH 6 , were incubated with a solution of $o$-dianisidine hydrochloride $(167 \mu \mathrm{g} / \mathrm{mL})$ and $0.0005 \%$ $\mathrm{H}_{2} \mathrm{O}_{2}$ (Sigma). An Epoch microplate reader (Biotek Instruments Inc.) was used to kinetically measure MPO activity at $460 \mathrm{~nm}$ with intervals of $15 \mathrm{~s}$ over a period of 5 min. All results were expressed as units of MPO per gland. A unit of MPO corresponding to the amount of enzyme that degrades $1 \mu \mathrm{mol}$ of $\mathrm{H}_{2} \mathrm{O}_{2} / \mathrm{min}$ at $25^{\circ} \mathrm{C}$, using the absorption coefficient of $11.3 \mathrm{~m} \mathrm{M}^{-1} \mathrm{~cm}^{-1}$ for 
$o$-dianisidine. Results were expressed as units of MPO per gram of gland.

\section{Preparation of Mammary Gland Homogenates for Cytokines and Chemokines Assays}

A fraction of mammary gland homogenates (5-6 infected glands per strain) was prepared for dosage of cytokines and chemokines using the mouse cytokinechemokine array 31-Plex (Eve Technologies, Calgary, AB, Canada). Samples were prepared by adding a 1:100 dilution of protease inhibitors to mammary gland homogenates. Samples were kept on ice and then centrifuged twice $15 \mathrm{~min}$ at $10,000 \times g$ at $4^{\circ} \mathrm{C}$. Supernatants were stored at $-80^{\circ} \mathrm{C}$ until used. The amount of proteins was measured for each sample by using the BCA kit (Pierce, Thermo-Fisher). Sample concentrations were harmonized to the lowest protein concentration measured and were then analyzed by Eve Technologies. Before analysis, corrections were applied on all data set to account for dilutions and weight of mouse mammary glands. Median of cytokine concentrations for each spa types were calculated. Concentration values were expressed in picograms per gram of mouse mammary gland.

\section{Statistical Analyses}

Statistical analyses were carried out with the GraphPad Prism software version 8 (GraphPad Software Inc.). Bacterial counts (cfu) were transformed in base 10 logarithm values before statistical analysis. Statistical tests used for the analysis of each experiment and significance are specified in the figure legends. The different levels of cytokines and chemokines induced by mouse IMI were categorized by using a principal component analysis (PCA) using the XLSTAT software for Excel (XLSTAT 2019, Microsoft Corp.). The principal components displaying the highest and second-highest percentage of variables were used. Both axes were chosen depending on the percentage of variability displayed by the scree plot. Pearson correlation was used to calculate the relationship between the variables and significance was fixed at $5 \%$.

\section{RESULTS}

\section{Strains Relatedness}

The general characteristics of Staph. aureus strains used in this study are shown in Table 1. A global analysis of whole-genome sequences is reported elsewhere (Park et al., 2020), and Table 1 summarizes the rel- evant information for the present study such as the CC and ST. The phylogenetic tree for the observed clades is shown in Figure 1, along with the relative similarity of the studied strains within each clade. Strains from spa types t267 and t359 (all CC97 and ST352) were found to be closely related. Other strains from CC97 and ST352 strains, such as t2445, were related as well, whereas those from spa types t13401 (CC97 and ST2187), were more distantly related to the other CC97 strains. The strain sa2117 of spa type t13401 was the exception, as it differed significantly from the rest of its spa group. All CC97 strains possessed the lukM gene, except for t13401 strains, and were of capsular type 5 and of the Agr group I. Strains from spa types t605 and t529 (all of Agr group II) were even more distant and were from clades CC126 (ST2270) and CC151 (ST151), respectively. The spa type t529 (capsular type 8) was the most commonly found among bovine mastitis isolates in Canada (Pichette-Jolette et al., 2019), and expresses several SAg genes, including seg, sec, selk, selm, seln, and selo (Table 1). In this group, strain sa3154 (CC151, ST351) was quite distinct (Figure 1), and contains additional enterotoxin/ SAg genes $\left(t_{s} t_{b o v}, s e c_{b o v}, s i l_{b o v}\right)$ associated with Staph. aureus pathogenesis island SaPIbov. As t13401, the spa type t605 was negative for lukM. The biofilm associated protein (Q79LN3_STAAU) gene (bap) was present only in t605 strains (capsular type 5). Strains from spa types t605 and t13401 produced the highest levels of biofilm although t13401 strains did not have the bap gene. Strains from t2445 produced the lowest level of biofilm (Table 1).

Given the redundance of Sdr proteins in Staph. aureus (SdrC [WP_001060440.1], SdrD [WP_000934474.1], SdrE [WP_000610294.1]) and hence their apparent importance in virulence (Sharp et al.,2012; Barbu et al., 2014), the distribution and sequence homologies of $3 \mathrm{Sdr}$ genes $(S d r C, S d r D$, and $S d r E$ ) were specifically investigated among the studied strains (Table 2). Gene $s d r C$ was found in all strains except one (strain sa3042) from the t13401 group (Table 2). All strains from t605 and t529 had mutations leading to an early stop codon in $s d r C$ (Supplemental Figure S1, https://doi.org/10 $.6084 / \mathrm{m} 9$.figshare.14981319.v1). Also, there was a deletion of 330 bases in the $s d r C$ gene of t2445 strains occurring in a repeated region of the protein rather than in the functional region (Supplemental Figure S1). The $s d r E$ gene was found in all spa types except for t13401. However, 2 strains of spa type t529 had no $s d r E$ gene and an allelic variant of $s d r E$ was noticed in the 5 other studied strains of that group (Table 2 and Supplemental Figure S1). Very similar sequences of SdrD were found in 3 spa types (t267, t2445 and t359). 


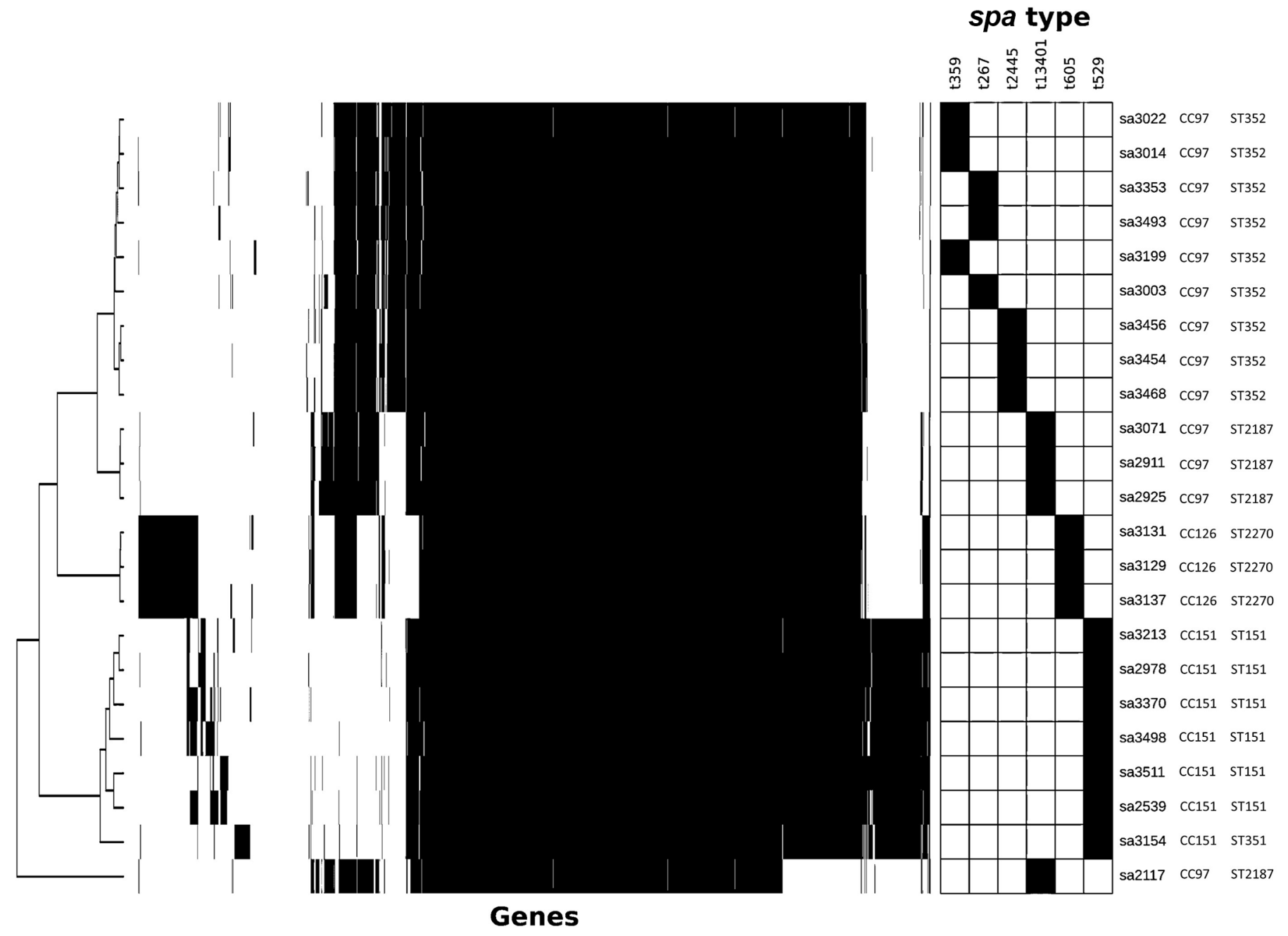

Figure 1. Phylogenetic tree and heatmap representation of gene compositions for the 23 Staphylococcus aureus genomes analyzed in this study. Genes were predicted using Roary and a total of 2,385 genes were defined as core genes. The heatmap was generated using R v3.6.3 and the gplots package using the absence or presence matrix of genes produced by Roary. Genes are represented by white and black bar for absence and presence, respectively. Staphylococcus aureus strains were clustered (complete method) by gene presence and absence using Manhattan distance; clustering dendrograms are shown on the left. On the right, the spa type is shown using a black box and clonal complexes (CC) and sequence types (ST) are indicated following the strain numbers.

Table 2. Distribution of $s d r$ genes among most prevalent Staphylococcus aureus spa types

\begin{tabular}{lcll}
\hline spa Type & $s d r C$ & $s d r D$ & $s d r E$ \\
\hline $\mathrm{t} 267$ & $5 / 5$ & $5 / 5$ & $5 / 5$ \\
$\mathrm{t} 359$ & $3 / 3$ & $3 / 3$ & $3 / 3$ \\
$\mathrm{t} 529^{1}$ & $7 / 7$ & $0 / 7$ & $5 / 7$ \\
$\mathrm{t} 605^{2}$ & $5 / 5$ & $0 / 5$ & $4 / 5$ \\
$\mathrm{t} 2445^{3}$ & $3 / 3$ & $3 / 3$ & $3 / 3$ \\
$\mathrm{t} 13401$ & $12 / 13$ & $0 / 13$ & $0 / 13$ \\
\hline
\end{tabular}

${ }^{1}$ All strains presented an early stop codon in $s d r C$. All 5 strains of $s d r E$ were allelic variants, and 2 strains (sa3511 and sa3370) had no $s d r E$ gene detected in their genomes.

${ }^{2}$ All strains presented an early stop codon in $s d r C$.

${ }^{3}$ All strains presented a deletion of 330 bases in the repeated region of $s d r C$ (see Supplemental Figure S1, https://doi.org/10.6084/m9 .figshare.14981319.v1).

\section{Staph. aureus Hemolytic Activity, Cellular Adherence, and Intracellular Persistence}

Since production of hemolysins plays a role in bacterial cytotoxicity in cell culture and will also influence the inflammation process in the mammalian host (Soe et al., 2021), Staph. aureus strains were first compared for their hemolytic activity on blood agar. All studied strains were capable of producing a $\beta$-hemolysis, however, the amount of hemolysin varied depending on the clonal origin of the strains (Figure 2). The spa types t529 and t2445 displayed the largest hemolysis diameters (medians of 17.3 and $18.0 \mathrm{~mm}$, respectively), whereas strains from spa type t605 (bap+ high biofilm producer) showed the smallest hemolysis diameters 
(median of $12.7 \mathrm{~mm}$ ). Strain sa3154 was analyzed separately because it possesses $10 \mathrm{SAg}$ genes (Table 1). Isolate sa3154 had much lower hemolytic activity than the rest of the t529 strains (Figure 2). A one-way ANOVA using Dunnett's multiple comparisons test showed statistical significance between t529 and t605 strains $(P=$ $0.024)$ and this difference was confirmed with a more conservative Kruskal-Wallis test $(P=0.043)$.

Adherence to MAC-T bovine mammary epithelial cells was measured $30 \mathrm{~min}$ postinfection. As shown in Figure 3A, the ability of strains from all spa types to adhere to MAC-T cells was relatively similar. On the other hand, the level of intracellular persistence measured $20 \mathrm{~h}$ postinfection showed some differences among strains and spa types. Strains from spa type t2445 showed higher intracellular persistence compared with the strains of the predominant Canadian spa type t529 (one-way ANOVA and Tukey's multiple comparison test, $P=0.03$; Figure $3 \mathrm{~B}$ ), but only a statistical trend was shown with the more conservative KruskalWallis test $(P=0.06)$. It is interesting to note that strain sa3456 (t2445) showed the strongest ability to persist within MAC-T cells compared with all other strains although one value was particularly high (Figure $3 \mathrm{~B}$ ). High variability was observed among strains from several spa types including t267, t359, t2445 and t13401, indicating that the relative intracellular persistence ability of Staph. aureus strains may not be associated with their clonal origin. The exception was spa type t529 that clustered strains demonstrating a similar low-intracellular persistence pattern.

\section{Colonization of Mouse Mammary Glands}

Each mouse mammary gland was infected with Staph. aureus and glands were then collected $10 \mathrm{~h}$ postinfection to simulate an early stage infection and at $20 \mathrm{~h}$ to measure bacterial colonization in a well-established infection. No difference in the early infection levels was noted between the Canadian spa types included in this study (data not shown). However, as illustrated in Figure 4 , significant differences were found in the levels of colonization at a later stage of infection. Because Staph. aureus strains are grouped into specific clonal lineages each possessing a remarkably identical genome because of a highly developed restriction-modification system that prevents, most of the time, horizontal gene transfer among lineages (Park et al., 2020), we considered that all isolates from the same spa type had an identical clonal origin and as such in Figure 4, each spa type is therefore represented by 10 to 12 repeats (2 strains per spa type, each colonizing 5-6 mammary glands). Excessive redness of the mammary glands was observed only with strains sa3511 and sa2539 (both spa

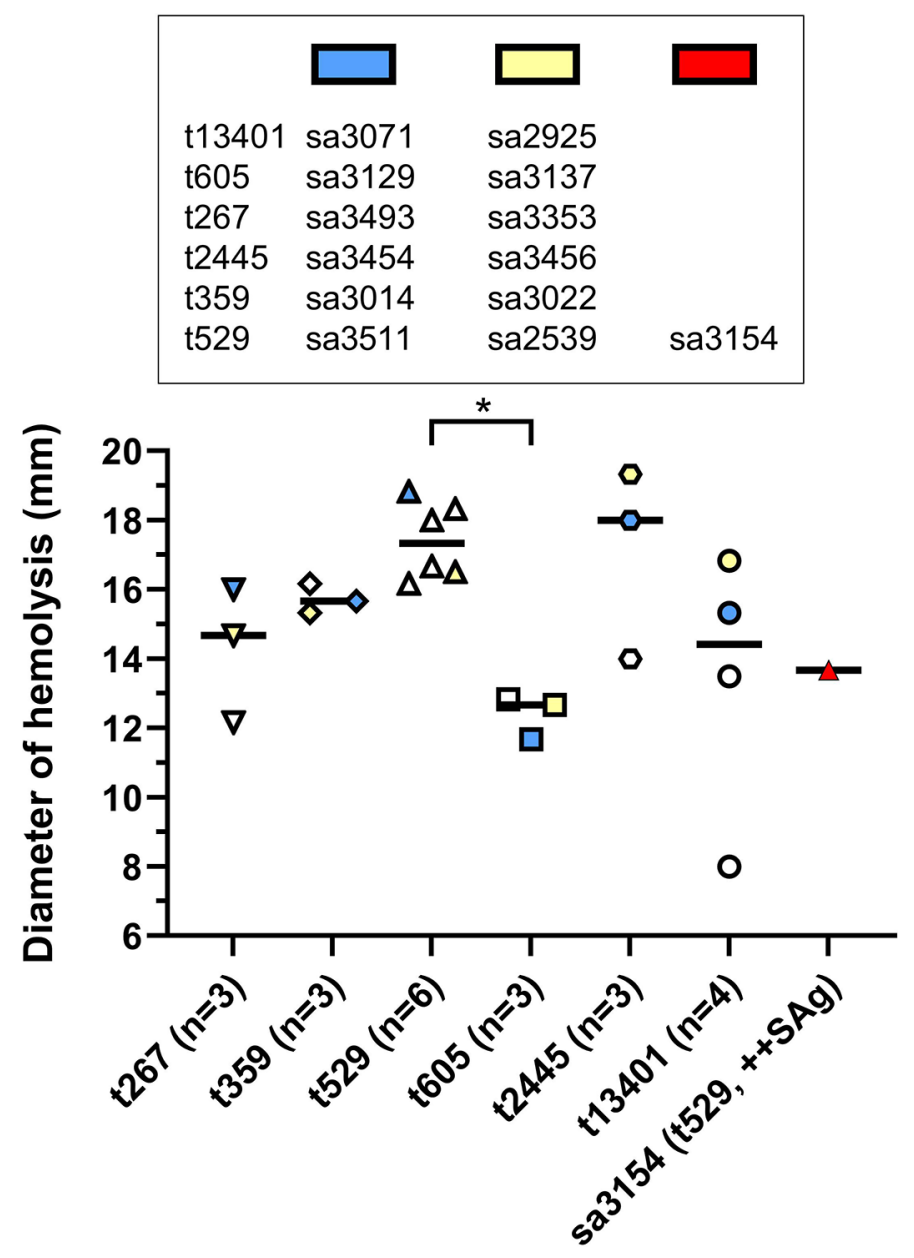

Figure 2. Diameters of Staphylococcus aureus $\beta$-hemolysis measured on blood agar plates for different spa types. Each dot corresponds to the mean value of the diameters of hemolysis recorded for each of the 23 Staph. aureus strains tested $[3$ replicates per strain, and the number of strains (n) per spa type is indicated]. The symbol colors are for the strains listed in the box and such strains are those that were used in all experiments including the mouse model of mastitis and evaluation of host cytokines (Figure 4-6). The clear symbols are for the other strains listed in Table 1. Strain sa3154 possessing 10 superantigen genes was analyzed separately. The horizontal bars correspond to the median for each spa type. The statistical test used for the analysis was a one-way ANOVA using Dunnett's multiple comparisons test. Each spa type was compared with spa type t529 acting as the reference $* P=0.024$.

type t529). Those strains, similarly to strains from spa type t359, exhibited the highest bacterial loads recovered from mammary glands $(P<0.006)$. On the other hand, strain sa3154 (spa type t529), which possesses at least $10 \mathrm{SAg}$ genes acquired by horizontal gene transfer (Table 1), showed a lower bacterial load than that seen with the 2 other strains of t529 $(P<0.0001)$. It should be noted that strains from the spa types that produced the highest amount of biofilm; that is, spa types t605 $(b a p+)$ and $13401(b a p-)$, had the lowest bacterial loads recovered from mammary glands (Figure 4). 

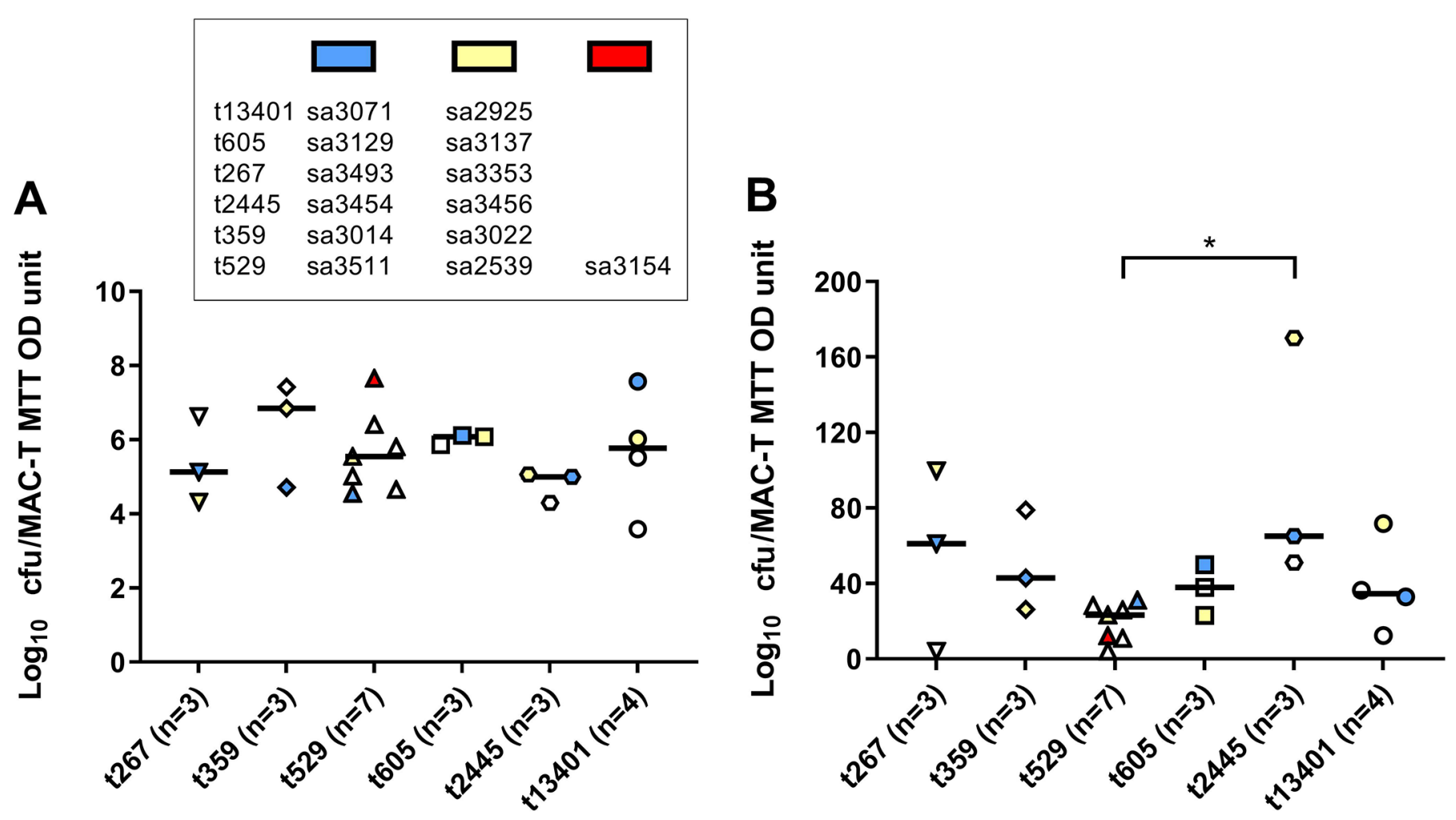

Figure 3. Adherence and intracellular persistence of different Staphylococcus aureus spa types on and in bovine mammary gland epithelial cells (MAC-T). (A) Number of cfu adhered on MAC-T cell surface 30 min postinfection and corrected for viable cells (MTT optical density units, see Materials and Methods). (B) Number of colony-forming units recovered within MAC-T cells 20 h postinfection (also corrected for viable cells). Each dot corresponds to the mean count (cfu) recorded for each Staph. aureus strain [2 replicates per strain, and the number of strains $(\mathrm{n})$ is indicated]. The symbol colors are for the strains listed in the box and such strains are those that were used in all experiments including the mouse model of mastitis and evaluation of host cytokines (Figure 4-6). The clear symbols are for the other strains listed in Table 1. The horizontal bars correspond to the median for each spa type. The statistical test used for the analysis was a one-way ANOVA using Tukey's multiple comparisons test. Each spa type was compared with all other spa types. ${ }^{*} P=0.03$.

\section{Inflammation of Mammary Glands During IMI}

The MPO produced primarily by neutrophils, was monitored to measure inflammation of mammary glands during IMI caused by the different spa types of Staph. aureus. Figure 5 shows that IMI caused by strains from spa type t267 were correlated with a significantly higher amount of MPO than t529 $(P=0.024)$, suggesting a higher local inflammatory response in mammary glands likely due to better neutrophil recruitment. However, note that the 2 highest MPO values measured for strain sa3493 (t267) originated from 2 mammary glands (left and right) of the same mouse. Hence, measurement of MPO released by neutrophils could not detect any major difference between spa types.

\section{Cytokines Analysis}

Pro-inflammatory cytokines and chemokines are essential for the recruitment of immune cells at the site of infection and they modulate the inflammatory response that normally leads to clearance of pathogens. Figure 6 shows the cytokines produced during IMI caused by each Staph. aureus spa type studied. The concentrations of 14 cytokines released in the mouse model of IMI were greater than $1,000 \mathrm{pg} / \mathrm{g}$ of glands (eotaxin, GCSF, IL-1 $\alpha$, IL-1 $\beta$, IL-6, IL-9, KC, LIF, LIX, MCP-1, MIP-1 $\alpha$, MIP-1 $\beta$, MIP-2, VEGF). The concentrations of IL-1 $\beta$ and IL- 6 released during IMI with strains from spa types t605 and t13401 and by strain sa3154 (t529, $10 \mathrm{SAgs}$ ) were lower than those from other strains from spa types t529 and t2445. The concentrations of IL- $1 \alpha$, LIX, MIP- $1 \alpha$ and MIP-1 $\beta$ released by spa type t529 IMIs were lower than those induced by other spa types.

As we studied the expression of a large panel of inflammatory mediators following infection with 13 strains, PCA was used to determine the correlation between the bacterial spa types and the cytokine responses they induced (specific cytokines and concentrations). For each bacterial strain, cytokine profiles were obtained from 5 to 6 infected glands (10-12 glands per spa type). As shown in Figure 7, several cytokines can be 
positively or negatively correlated with some spa types. Using PCA analysis, strains eliciting similar cytokine expression profiles (specific cytokines and their level of expression or concentration) were grouped together. The quarters shown in Figure 7 were used to aid in the visualization of positive, negative, and opposing correlations. Strains that elicited similar immune responses were clustered together into the same quarter, whether they belonged to the same spa type or not. In Figure 7, the 4 quarters (groups 1-4) are represented: both high biofilm producers (t605 and t13401 strains) and t267 strains were clustered in group 1, strains from the

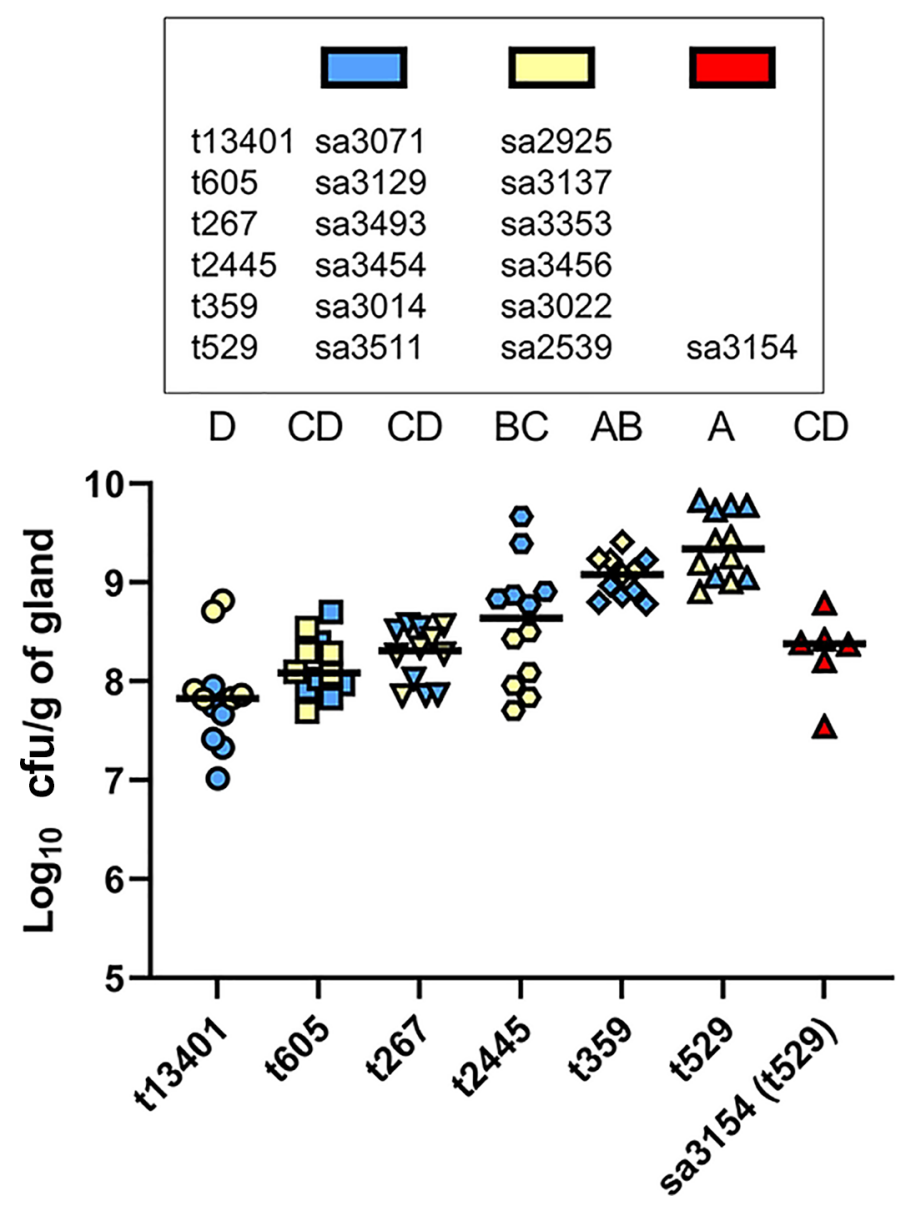

Figure 4. Bacterial load in mouse mammary glands $20 \mathrm{~h}$ after IMI. Each dot corresponds to one infected mammary gland (5-6 glands per strain for a total of 10-12 glands infected per spa type). Each color represents all mammary glands infected by the same strain within each spa type (see strain identification in the box). Strain sa3154 possessing 10 superantigen genes was analyzed separately. Horizontal bars represent the median for each spa type. The statistical test used for the analysis was a one-way ANOVA using Tukey's multiple comparisons test. Each spa type was compared with all other spa types. No significant difference was observed between spa types with the same letter and spa types with different letters were significantly different $P<0.006$.

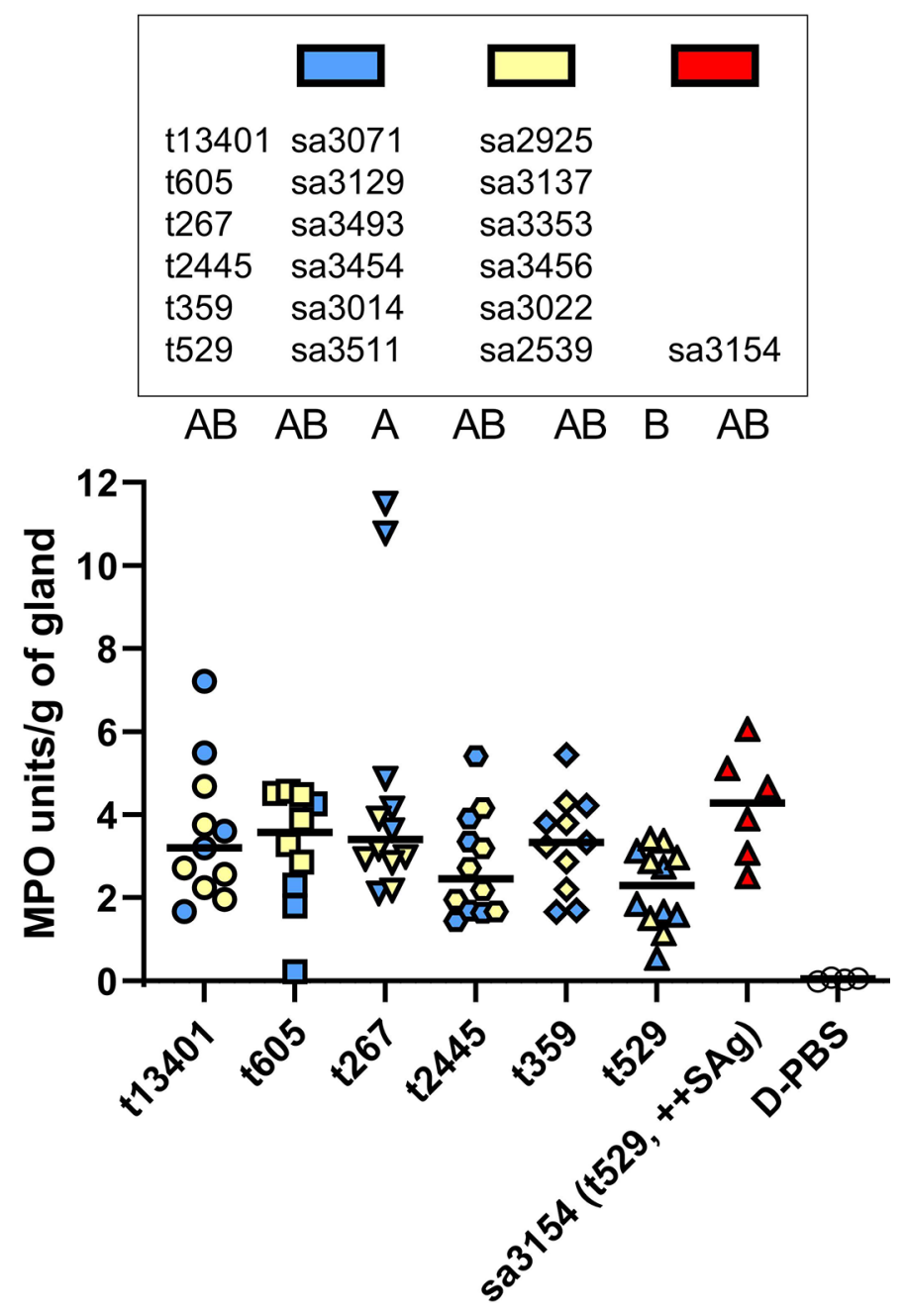

Figure 5. Inflammation levels as measured by myeloperoxidase (MPO) activity in infected mammary glands $20 \mathrm{~h}$ postinfection. The amount of MPO units released by neutrophils was used as a local inflammation marker. Each color represents all mammary glands infected by the same strain within each spa type (see strain identification in the box). Strain sa3154 possessing 10 superantigen genes was analyzed separately. Dulbecco's PBS (D-PBS) was injected for the mock infections (control mouse group without bacteria). Horizontal bars represent the median for each spa type. The statistical test used for the analysis was a one-way ANOVA using Tukey's multiple comparisons test. Each spa type was compared with all other spa types. No significant difference was observed between spa types with the same letter and spa types with different letters were significantly different $(P=0.024)$.

most prevalent spa type t529 (strain sa3154 excluded) were found in group 2, and strains from spa type t2445 were found in groups 2 and 3, whereas t359 strains were found in groups 1 and 4. In Figure 7, the vectors show the cytokine profiles that differentiate the host responses associated with the various strains. This means that strains that can harm the host or that produce a variety of virulence factors are expected to elicit strong 
and specific cytokine responses. As a result, it is worth noting that the t529 strain sa3154, which possesses by far the greatest number of superantigens (10 SAgs), is found isolated in the center of the 4 quarters (i.e., no cytokine profile association), whereas all other strains could be associated with specific cytokine expression profiles. Group 1 showed a positive correlation with expression of G-CSF, KC, IL-5, LIF and eotaxin and a negative correlation for expression of IL-4, IL-12(p40) and IL-13 (Figure 7). For group 2, a positive correlation was observed for expression of IL-1 $\beta$, IL-6, M-CSF, and IL-12(p70), whereas a negative correlation was found with LIF (Figure 7).

\section{DISCUSSION}

Staphylococcus aureus is a pathogen with many geographical and host-specific clonal origins. Previous studies have identified 6 main spa types in Canadian dairy cattle: t529, t267, t359, t605, t2445, and t13401 (Said et al., 2010; Veh et al., 2015; Pichette-Jolette et al., 2019; Naushad et al., 2020). With the exception of t605, CC126, these spa types are from the CC151 and CC97, which are also the most widespread CC in Europe (Hoekstra et al., 2020). Some of our previous studies attempted to predict the duration of IMI based on the genotypic and phenotypic characteristics of Staph.

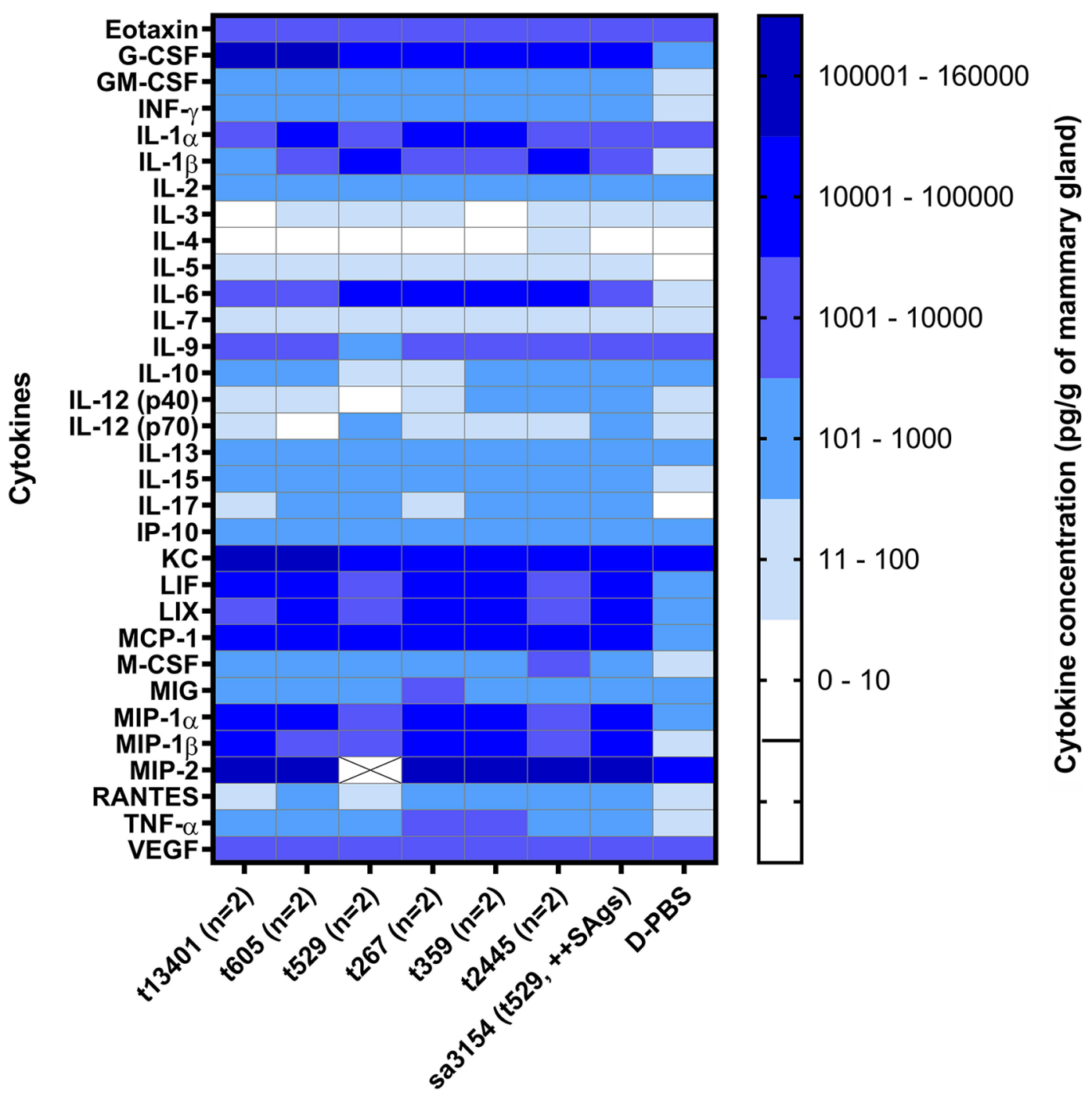

Figure 6. Cytokine concentrations detected in infected mammary glands $20 \mathrm{~h}$ postinfection. Each box corresponds to a range of concentrations (pg/g of mammary gland) measured for all mammary glands infected by all the strains within each spa type (2 strains for each spa types, additionally to strain sa3154, which possessed 10 superantigen genes and which was analyzed separately). This represented 10 to 12 glands per spa type. Results for strain sa3154 (t529) are from 6 glands. The darkest boxes represent the highest concentrations of cytokines measured in the mammary glands (see scale on the right). The crossed box corresponds to a high out-of-range value. Dulbecco's PBS (D-PBS) was injected for the mock infections (control mice group without bacteria; data from 4 glands). 
aureus isolates from different quarter milk samples collected over 2 years from 91 farms (Veh et al., 2015; Pichette-Jolette et al., 2019). Such retrospective studies have only been partially successful in associating the phenotype or genotype of Staph. aureus isolates with the observed disease outcome in cows (clinical, subclinical, persistent). The reasons for this are multiple (herd, farm management, treatment, and level of host immune resistance and response). Similarly, a recent pan-genomic study on bovine Staph. aureus isolates from milk could not find any correlation between the virulence potential of isolates (total virulence genes minus core genome virulence genes) and SCC in milk as the proxy for disease severity (Naushad et al., 2020). Likewise, Hoekstra et al. (2020), could identify a variety of genes associated with clinical mastitis but many of these genes were sometimes also present in CC associated with a subclinical disease. Here, we have taken a step back to better characterize the phenotype and genotype of Staph. aureus spa types encountered in Canadian dairy herds. We used in vitro and in vivo mastitis models that removed the "cow, farm, and management effects" from the analysis and demonstrated significant differences in the virulence potential of Staph. aureus spa types.

The ability of Staph. aureus to adhere, invade and persist in host cells allows the bacteria to escape the immune system and antibiotic therapies (Proctor et al., 2006). Both adherence and intracellular persistence abilities of the Staph. aureus spa types were investigated using the bovine mammary gland epithelial MAC-T cell line. No significant differences were observed for the adherence ability of the strains on the MAC-T cell surface, but some spa types showed differences in intracellular persistence. Only spa type t2445 resulted in significantly higher counts in MAC-T cells compared with those from spa type t529, which was inversely the least persistent. This property suggests that strains from t2445 could establish chronic IMI (Kerro Dego et al., 2002; Rainard et al., 2018). The high variability of persistence among spa types t267, t359, and t13401

\section{Biplot (axes F1 and F2: 53,53 \%)}

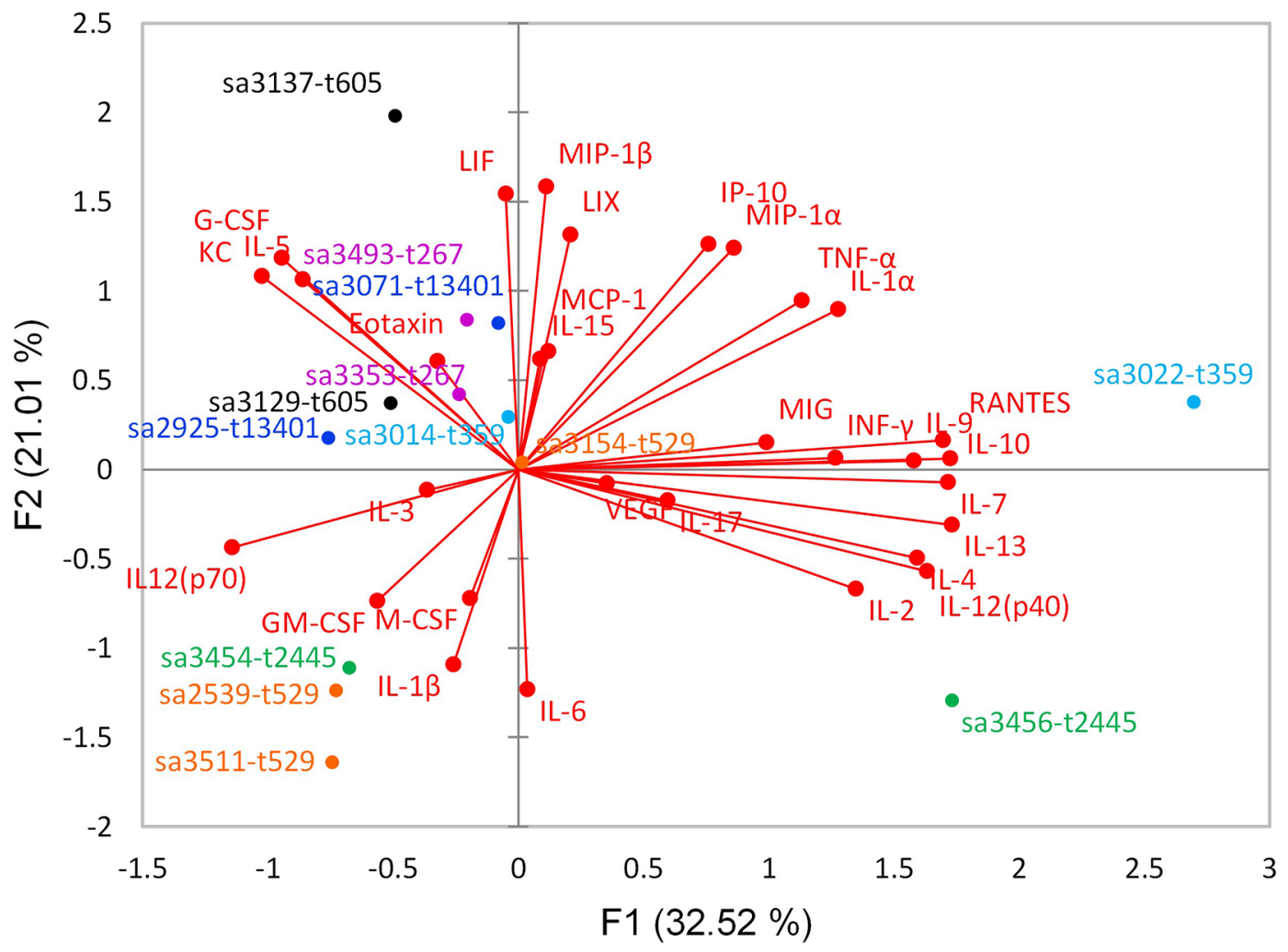

Figure 7. Principal component analysis (PCA) of cytokine levels detected in infected mammary glands 20 h postinfection. Vectors representing the concentration of various cytokines measured in homogenates of infected mammary glands are shown in red. The length of each vector is associated with the cytokine concentration measured, and the angles indicate the positive or negative correlations between each cytokine. The biplot is combining spa types and vectors based on the PCA correlation. Strains from the same spa type are indicated by the same color scheme. Axes F1 and F2 are the principal components displaying the highest and second-highest percentage of variables (32.52\% and $21.01 \%$, respectively). 
suggest that the clonal origin is not the only variable that needs to be taken into account for Staph. aureus persistence in epithelial cells. The hemolytic activity of each strain is an example of such variables because Staph. aureus $\alpha$-hemolysin contributes to host cell lysis. Although MAC-T cell killing was considered in our intracellular persistence assay, strains from t529 were among the most hemolytic on blood agar plates (Figure 2) and were accordingly the least persistent inside cells (Figure 3B). Indeed, production of $\alpha$-hemolysin leads to cell death and release of intracellular bacteria (Soe et al., 2021).

Our mouse model of IMI was used to investigate the ability of Staph. aureus strains to infect and colonize the mammary glands, to evaluate the local inflammation and to measure some markers of the host immune response (cytokines) induced by each spa type. The lactating mouse model is a well-established model for the investigation of host-pathogen interactions during IMI (Brouillette and Malouin, 2005). In our study, extensive tissue redness was observed only on mammary glands infected by strains sa3511 and sa2539 (both from spa type t529). Strains from spa type t529 carried more SAg genes than any of the other spa types (Table 1). Wilson et al. (2018) have shown that SAg expressed by Staph. aureus strains can stimulate different subfamilies of T lymphocytes with the consequence of overstimulating the immune system and could favor the occurrence of clinical cases of mastitis. Strains from spa type (t529), which is part of the sequence type ST151, carry the egc cluster of SAg (seg, sei, sen, sem, seo) (Wilson et al., 2018; Naushad et al., 2020; Park et al., 2020). This observation therefore appears to fit well with the high virulence of our t529 strains in the mouse mastitis model. On the other hand, the t529 strain sa3154 is part of ST 351 and possesses the Staph. aureus pathogenicity island $\mathrm{SaPI}_{\mathrm{bov}}$ carrying the $\mathrm{SAgs}$ genes $t s t_{\mathrm{bov}}$, $s e c_{\text {bov }}$, seil bov in addition to the egc cluster for a total of at least $10 \mathrm{SAg}$ genes (Table 1). Strain sa3154 is similar to the well-studied bovine strain RF122, and Wilson et al. (2018) showed that the $3 \mathrm{SAg}$ encoded by SaPIbov alone could activate 13 of 18 bovV $\beta$ T cell subfamilies in comparison to the activation of only 11 of 18 subfamilies by all the SAg of the egc cluster. This may indicate that strain sa3154 is better equipped for immune evasion but the reason why it showed less colonization and inflammation, and no redness of the gland in contrast to the other strains of t529 in our mouse mastitis model is unclear. One possible reason is that sa3154 showed the lowest hemolytic activity among spa type t529 strains (Figure 2). Hemolysins are associated with the presence of injuries on the epithelium of the mammary gland and local inflammation. Such tissue injuries are known to promote the loss of tissue tightness which leads to the presence of blood in milk and contributes to the manifestation of the clinical signs of mastitis (Rainard et al., 2018).

The biofilm hyperproducer strains from spa types t605 and t13401 were the least able to multiply in mouse mammary glands (Figure 4). Those isolates do not carry the egc cluster or lukM coding for the bovine specific leukocidin LukMF', but they are still among the predominant spa types found in Canadian herds (Pichette-Jolette et al., 2019). These results suggest an inverse correlation between the amount of biofilm produced and the number of colony-forming units recovered from infected mammary glands. Similarly, Pereyra et al. (2017) found that a Staph. aureus isolate that produced a large amount of biofilm was associated with a lower likelihood of mammary gland injury. However, the type of immune response it triggered was consistent with chronic mastitis. These results suggest that strains from spa types t605 and t13401 are more likely to induce chronic mastitis compared with those from spa types t529 and t359, which are inversely the most virulent in our mouse model of IMI (Figure 4). Indeed, Pichette-Jolette et al. (2019) has previously shown that spa type t13401 was more likely to persist in cows compared with those from spa type t529 and t359.

Serine-aspartate rich (Sdr) proteins are important virulence factors in Staph. aureus (Foster et al., 2014; Foster, 2019). Because SdrC, SdrD and SdrE may play a variety of roles in pathogenesis (biofilm formation, adhesion to host molecules and immune evasion mechanisms) we attempted to correlate their presence or sequence divergence (Table 2 and Supplemental Figure S1) to the phenotypes we observed in this study. Among the principal observations, 3 spa types of the CC97 clade (t267, t2445, t359; all ST352) had all 3 genes $(s d r C, s d r D, s d r E)$ in their genomes but the strains from these spa groups were not the most virulent in the mastitis mouse model (Figure 4). However, the spa type t13401 (also CC97 but ST2187) did not possess $s d r D$ and $s d r E$ and was the least virulent (Figure 4). Noteworthy, there was a deletion of 330 bases in the $s d r C$ gene of $\mathrm{t} 2445$ strains occurring in a repeated region of the protein rather than in the functional region. Interestingly, this spa type (t2445) was the weakest biofilm producer among the spa groups analyzed (Table $1)$. Whether or not this deletion affects the formation of biofilm is difficult to tell at this time. All strains from t605 (CC126) and t529 (CC151) presumably had a nonfunctional SdrC protein since they show mutations leading to an early stop codon in $s d r C$ (Table 2 and Supplemental Figure S1). Similarly, Xue et al. (2011) reported deletions and stop codons within the 
$s d r C$ genes of many Staph. aureus isolates. This means that spa types t605 and t529 only possess SdrE as member of the serine-aspartate rich proteins. Furthermore, 2 of the 7 strains of t529 had no SdrE, whereas the other 5 strains possessed an allelic variant of $s d r E$. This is intriguing because t529 was the most virulent spa type (Figure 4). This SdrE variant is characterized by a modified functional domain of the protein and was previously associated with strains leading to bone infections in humans (Tung et al., 2000; Tristan et al., 2003). However, the presence of this variant does not appear to enhance virulence in the mouse model. In fact, no significant difference was found between strain sa2539 (detaining the allelic variant) and strain 3511 having no SdrE (Figure 4).

Neutrophils are one of the first host immune cells to be recruited locally during an IMI. As a part of the innate immunity, they are involved in the phagocytosis of both infected cells and pathogens. They also lead to local inflammation by the release of MPO to kill extracellular bacteria, and by the release of several cytokines and chemokines involved in chemotaxis and regulation of inflammation. As shown in Figure 5, only one significant difference was observed with a higher amount of MPO released for strains from t267 compared with those from $\mathrm{t} 529$. Overall, however, measurement of MPO released by neutrophils could not detect any major difference between spa types.

Cytokines are involved in regulation of inflammation, immune cells recruitment and their activation. They are an important part of the host's ability to clear pathogens. However, in the case of chronic inflammatory diseases such as it is often the case with Staph. aureus IMI, a loss of pro- and anti-inflammatory cytokines regulation and a failure to induce a strong immune response could explain the occurrence of recurrent infections or the increase in duration of the disease. Our data show that all Staph. aureus strains can induce TNF- $\alpha$, IL-1 $\beta$, and IL-6, which are involved in innate immune responses (Figure 6). A consistent level of IFN- $\gamma$ observed for all strains also suggests that the NK cells were activated similarly to other immune cells involved in the innate response (Figure 6). In addition, the high MCP concentration measured in glands (Figure 6), suggests that all strains can recruit inflammatory macrophages from the bone marrow. The statistical analysis by PCA allowed some strains to be clustered based on the cytokine expression profiles they induced. High biofilm producers (t605 and t13401) and strains from $t 267$ (i.e., group 1, Figure 7), led to profiles that were correlated with several cytokines involved in immune cells recruitment (eotaxin, KC), neutrophil proliferation (G-CSF), B lymphocyte proliferation (IL5), inflammation (KC, LIF), and healing (KC) (Figure
7). Strains sa3511 and sa2539 of spa type t529 (CC151, ST151), such as group 2 (Figure 7), induced cytokines involved in pro-inflammatory response and fever (IL13, IL-6), monocytes proliferation (GM-CSF) and the naïve $\mathrm{T}$ lymphocyte differentiation in Th1 (IL-12; Figure 7). As reported by Oviedo-Boyso et al. (2007), the immune response induced during Staph. aureus IMI (leading to clinical or subclinical mastitis) is associated with an increase in milk SCC, an increase of IL-1 IL-12, TNF- $\alpha$, C5a, and IgG2 concentrations, and the recruitment of $\mathrm{CD}^{+}$lymphocytes. Thus, this immune response is similar to that we have observed for group 2 strains from t529 with the exception of strain sa3154 (CC151, ST 351 ) possessing more SAg genes, and which was not associated with any specific cytokine expression profile. IL-1 $\beta$ is produced by macrophages and epithelial cells and has previously been associated with the first stage of Staph. aureus IMIs (Oviedo-Boyso et al., 2007). Interleukin-6, also produced by macrophages, has been associated with septic shock during the acute phase of Staph. aureus infections and facilitate the replacement of neutrophils to prevent deleterious effects of inflammation (Oviedo-Boyso et al., 2007). In addition, IL-12 can stimulate the production of IFN- $\gamma$ and TNF- $\alpha$ (both pro-inflammatory cytokines) from Th1 lymphocytes and NK cells. Interleukin-12 may also enhance cytotoxicity by both NK cells and Tc CD8 ${ }^{+}$ lymphocytes, act as a mediator between acquired and innate immunity, and may be involved in the regulation of lymphocyte differentiation. These observations suggest that most strains from t529 may lead to acute mastitis with severe symptoms. Similarly, cytokines IL-1 $\beta$, IL-12 and TNF- $\alpha$ were associated with clinical mastitis caused by several other bacterial pathogens such as Streptococcus uberis, Escherichia coli, Klebsiella pneumoniae, and Pseudomonas aeruginosa (OviedoBoyso et al., 2007).

This study examined proxies for host-pathogen interactions led by the major Staph. aureus spa types responsible for IMI in Canadian dairy herds using in vitro and in vivo mastitis models. These models enabled the search for associations between spa types and their ability to invade and persist in both mammary epithelial cells and mouse mammary glands, though our interpretations and possible extrapolation of results to cows should be used with caution. Also, the host (mouse) immune response induced by Staph. aureus strains of different clonal origins was measured and analyzed. Results show that most strains from the spa type t529 (CC151, ST151) have characteristics that are often correlated with clinical mastitis cases, whereas characteristics of strains from spa types t267, t605, and t13401 are generally correlated with subclinical or chronic mastitis. The exception was with strain 
sa3154, which is part of the t529 spa type but of the sequence type ST351. This strain possesses at least 10 SAg genes and produced a moderate level of infection similar to t267 and induces a low immune response. Isolates positive for $t s t$ such as sa3154 are however rare among t529 isolates in Canada (9/115 isolates [8\%]; Pichette-Jolette et al., 2019). Based on the phenotypic data collected in this study, the virulence potential of Staph. aureus strains can be ranked as follows:

$$
\begin{gathered}
\mathrm{t} 529(\mathrm{ST} 151)>\mathrm{t} 359>\mathrm{t} 2445>\mathrm{t} 529(\mathrm{ST} 351)= \\
\mathrm{t} 267=\mathrm{t} 605>\mathrm{t} 13401 .
\end{gathered}
$$

This is in agreement, in part, with our retrospective study of bovine mastitis cases which showed that strains from t529 and t359 were less likely to cause persistent IMI compared with strains from t13401 and that clinical mastitis was more often associated with lukM positive strains (Pichette-Jolette et al., 2019). Strain sa3154, which carries both the egc cluster of SAgs as well as SaPIbov ( sst $_{\text {bov }}, \sec _{\text {bov }}, s$ seil $\left._{b o v}\right)$ and appears to be less virulent than other t529 strains or at least in the mouse model, is an exception. Retrospectively, it would have been nice to include more tst-positive strains in our work to corroborate findings on strain sa3154 but at the onset of this study, we did not realize how different this strain would be from the other t529 strains. This type of strain could be easily identified by a PCR of the tst gene.

Thus, identification of the spa type at an early stage in the diagnosis of Staph. aureus IMI might help to support management decisions based on a certain prediction of disease outcome. The observations and assumptions made here should now be validated in studies where the Staph. aureus lineages of interest are randomly assigned to a standardized cow population to assess and verify clinical outcomes. Although spa typing is simple, an equivalent rapid and cost-effective alternative method for typing strains has also been described (ribosomal-spacer PCR; Fournier et al., 2008; Boss et al., 2016). Predicting the outcome of the disease by determining the clonal lineage of isolates could significantly reduce the economic losses caused by IMI in bovine dairy herds.

\section{ACKNOWLEDGMENTS}

This research was funded by the Natural Sciences and Engineering Research Council of Canada (NSERC grant to FM No. 2015-05916). The authors also acknowledge support from the Mastitis Network (Université de Montréal, St-Hyacinthe, QC, Canada) as well as from $\mathrm{Op}^{+}$lait, the FRQNT Regroupement stratégique pour un lait de qualité optimale (Université de Montréal, St-Hyacinthe, QC, Canada). ED and ADD are grateful for receiving studentships from $\mathrm{Op}^{+}$lait. $\mathrm{ED}$ and $\mathrm{ADD}$ also obtained studentships from the NSERC-CREATE program in milk quality. We also thank Suzanne Chamberland for critical review of the manuscript. We thank Calcul Québec, Compute Canada, and the Centre de Calcul Scientifique of the Université de Sherbrooke for access and technical support for using the Mammouthmp2 supercomputer. The authors have not stated any conflicts of interest.

\section{REFERENCES}

Aghamohammadi, M., D. Haine, D. F. Kelton, H. W. Barkema, H. Hogeveen, G. P. Keefe, and S. Dufour. 2018. Herd-level mastitisassociated costs on Canadian dairy farms. Front. Vet. Sci. 5:100. https://doi.org/10.3389/fvets.2018.00100.

Aires-de-Sousa, M., K. Boye, H. de Lencastre, A. Deplano, M. C. Enright, J. Etienne, A. Friedrich, D. Harmsen, A. Holmes, X. W. Huijsdens, A. M. Kearns, A. Mellmann, H. Meugnier, J. K. Rasheed, E. Spalburg, B. Strommenger, M. J. Struelens, F. C. Tenover, J. Thomas, U. Vogel, H. Westh, J. Xu, and W. Witte. 2006. High interlaboratory reproducibility of DNA sequence-based typing of bacteria in a multicenter study. J. Clin. Microbiol. 44:619-621. https://doi.org/10.1128/JCM.44.2.619-621.2006.

Arciola, C. R., D. Campoccia, S. Ravaioli, and L. Montanaro. 2015. Polysaccharide intercellular adhesin in biofilm: Structural and regulatory aspects. Front. Cell. Infect. Microbiol. 5:7. https://doi .org/10.3389/fcimb.2015.00007.

Baby, V., F. Labroussaa, J. Brodeur, D. Matteau, G. Gourgues, C. Lartigue, and S. Rodrigue. 2018. Cloning and transplantation of the Mesoplasma florum genome. ACS Synth. Biol. 7:209-217. https://doi.org/10.1021/acssynbio.7b00279.

Bannerman, D. D. 2009. Pathogen-dependent induction of cytokines and other soluble inflammatory mediators during intramammary infection of dairy cows. J. Anim. Sci. 87(suppl_13):10-25. https:/ /doi.org/10.2527/jas.2008-1187.

Bannerman, D. D., M. J. Paape, J.-W. Lee, X. Zhao, J. C. Hope, and P. Rainard. 2004. Escherichia coli and Staphylococcus aureus elicit differential innate immune responses following intramammary infection. Clin. Diagn. Lab. Immunol. 11:463-472. https://doi.org/ 10.1128/CDLI.11.3.463-472.2004.

Bannerman, D. D., H. R. Springer, M. J. Paape, A. C. Kauf, and J. P. Goff. 2008. Evaluation of breed-dependent differences in the innate immune responses of Holstein and Jersey cows to Staphylococcus aureus intramammary infection. J. Dairy Res. 75:291-301. https:/ /doi.org/10.1017/S0022029908003427.

Barbu, E. M., C. Mackenzie, T. J. Foster, and M. Höök. 2014. SdrC induces staphylococcal biofilm formation through a homophilic interaction. Mol. Microbiol. 94:172-185. https://doi.org/10.1111/ mmi.12750.

Besemer, J., A. Lomsadze, and M. Borodovsky. 2001. GeneMarkS: A self-training method for prediction of gene starts in microbial genomes. Implications for finding sequence motifs in regulatory regions. Nucleic Acids Res. 29:2607-2618. https://doi.org/10.1093/ nar/29.12.2607.

Bolger, A. M., M. Lohse, and B. Usadel. 2014. Trimmomatic: A flexible trimmer for Illumina sequence data. Bioinformatics 30:21142120. https://doi.org/10.1093/bioinformatics/btu170.

Boss, R., A. Cosandey, M. Luini, K. Artursson, M. Bardiau, F. Breitenwieser, E. Hehenberger, Th. Lam, M. Mansfeld, A. Michel, G. Mösslacher, J. Naskova, S. Nelson, O. Podpečan, A. Raemy, E. Ryan, O. Salat, P. Zangerl, A. Steiner, and H. U. Graber. 2016. Bovine Staphylococcus aureus: Subtyping, evolution, and zoonotic transfer. J. Dairy Sci. 99:515-528. https://doi.org/10.3168/jds .2015-9589. 
Brouillette, E., G. Grondin, C. Lefebvre, B. G. Talbot, and F. Malouin. 2004. Mouse mastitis model of infection for antimicrobial compound efficacy studies against intracellular and extracellular forms of Staphylococcus aureus. Vet. Microbiol. 101:253-262. https: //doi.org/10.1016/j.vetmic.2004.04.008.

Brouillette, E., and F. Malouin. 2005. The pathogenesis and control of Staphylococcus aureus-induced mastitis: Study models in the mouse. Microbes Infect. 7:560-568. https://doi.org/10.1016/j .micinf.2004.11.008.

Canning, P., R. Hassfurther, T. TerHune, K. Rogers, S. Abbott, and D. Kolb. 2017. Efficacy and clinical safety of pegbovigrastim for preventing naturally occurring clinical mastitis in periparturient primiparous and multiparous cows on US commercial dairies. J. Dairy Sci. 100:6504-6515. https://doi.org/10.3168/jds.2017-12583.

Côté-Gravel, J., E. Brouillette, N. Obradović, C. Ster, B. G. Talbot, and F. Malouin. 2016. Characterization of a vraG mutant in a genetically stable Staphylococcus aureus small-colony variant and preliminary assessment for use as a live-attenuated vaccine against intrammamary infections. PLoS One 11:e0166621. https://doi .org/10.1371/journal.pone.0166621.

Côté-Gravel, J., and F. Malouin. 2019. Symposium review: Features of Staphylococcus aureus mastitis pathogenesis that guide vaccine development strategies. J. Dairy Sci. 102:4727-4740. https://doi .org/10.3168/jds.2018-15272.

Curone, G., J. Filipe, P. Cremonesi, E. Trevisi, M. Amadori, C. Pollera, B. Castiglioni, L. Turin, V. Tedde, D. Vigo, P. Moroni, A. Minuti, V. Bronzo, M. F. Addis, and F. Riva. 2018. What we have lost: Mastitis resistance in Holstein Friesians and in a local cattle breed. Res. Vet. Sci. 116:88-98. https://doi.org/10.1016/j .rvsc.2017.11.020.

Foster, T. J. 2019. The MSCRAMM family of cell-wall-anchored surface proteins of gram-positive cocci. Trends Microbiol. 27:927-941. https://doi.org/10.1016/j.tim.2019.06.007.

Foster, T. J., J. A. Geoghegan, V. K. Ganesh, and M. Höök. 2014. Adhesion, invasion and evasion: The many functions of the surface proteins of Staphylococcus aureus. Nat. Rev. Microbiol. 12:49-62. https://doi.org/10.1038/nrmicro3161.

Fournier, C., P. Kuhnert, J. Frey, R. Miserez, M. Kirchhofer, T. Kaufmann, A. Steiner, and H. U. Graber. 2008. Bovine Staphylococcus aureus: Association of virulence genes, genotypes and clinical outcome. Res. Vet. Sci. 85:439-448. https://doi.org/10.1016/j .rvsc.2008.01.010.

Gardner, S. N., and T. Slezak. 2014. Simulate_PCR for amplicon prediction and annotation from multiplex, degenerate primers and probes. BMC Bioinformatics 15:237. https://doi.org/10.1186/1471 -2105-15-237.

Herbert, S., A.-K. Ziebandt, K. Ohlsen, T. Schäfer, M. Hecker, D. Albrecht, R. Novick, and F. Götz. 2010. Repair of global regulators in Staphylococcus aureus 8325 and comparative analysis with other clinical isolates. Infect. Immun. 78:2877-2889. https://doi.org/10 .1128/IAI.00088-10.

Hoekstra, J., V. Rutten, L. Sommeling, T. van Werven, M. Spaninks, B. Duim, L. Benedictus, and G. Koop. 2018. High production of LukMF $^{\prime}$ in Staphylococcus aureus field strains is associated with clinical bovine mastitis. Toxins (Basel) 10:200. https://doi.org/10 $.3390 /$ toxins 10050200 .

Hoekstra, J., A. L. Zomer, V. P. M. G. Rutten, L. Benedictus, A. Stegeman, M. P. Spaninks, T. W. Bennedsgaard, A. Biggs, S. De Vliegher, D. H. Mateo, R. Huber-Schlenstedt, J. Katholm, P. Kovács, V. Krömker, G. Lequeux, P. Moroni, L. Pinho, S. Smulski, K. Supré, J. M. Swinkels, M. A. Holmes, T. J. G. M. Lam, and G. Koop. 2020. Genomic analysis of European bovine Staphylococcus aureus from clinical versus subclinical mastitis. Sci. Rep. 10:18172. https://doi.org/10.1038/s41598-020-75179-2.

Jacques, M., V. Aragon, and Y. D. N. Tremblay. 2010. Biofilm formation in bacterial pathogens of veterinary importance. Anim. Health Res. Rev. 11:97-121. https://doi.org/10.1017/S1466252310000149.

Kerro Dego, O., J. E. van Dijk, and H. Nederbragt. 2002. Factors involved in the early pathogenesis of bovine Staphylococcus aureus mastitis with emphasis on bacterial adhesion and invasion. A re- view. Vet. Q. 24:181-198. https://doi.org/10.1080/01652176.2002 .9695135 .

Kubica, M., K. Guzik, J. Koziel, M. Zarebski, W. Richter, B. Gajkowska, A. Golda, A. Maciag-Gudowska, K. Brix, L. Shaw, T. Foster, and J. Potempa. 2008. A potential new pathway for Staphylococcus aureus dissemination: The silent survival of $S$. aureus phagocytosed by human monocyte-derived macrophages. PLoS One 3:e1409. https://doi.org/10.1371/journal.pone.0001409.

Melchior, M. B., J. Fink-Gremmels, and W. Gaastra. 2007. Extended antimicrobial susceptibility assay for Staphylococcus aureus isolates from bovine mastitis growing in biofilms. Vet. Microbiol. 125:141149. https://doi.org/10.1016/j.vetmic.2007.05.019.

Mitchell, G., A. Fugère, K. Pépin Gaudreau, E. Brouillette, E. H. Frost, A. M. Cantin, and F. Malouin. 2013. SigB is a dominant regulator of virulence in Staphylococcus aureus small-colony variants. PLoS One 8:e65018. https://doi.org/10.1371/journal.pone .0065018 .

Moisan, H., E. Brouillette, C. L. Jacob, P. Langlois-Bégin, and S. Michaud., F. and Malouin. 2006. Transcription of virulence factors in Staphylococcus aureus small-colony variants isolated from cystic fibrosis patients is influenced by $\operatorname{sigB}$. J. Bacteriol. 188:64-76. https: //doi.org/10.1128/JB.188.1.64-76.2006.

Mühl, H., and J. Pfeilschifter. 2003. Anti-inflammatory properties of pro-inflammatory interferon- $\gamma$. Int. Immunopharmacol. 3:12471255. https://doi.org/10.1016/S1567-5769(03)00131-0.

Naushad, S., D. B. Nobrega, S. A. Naqvi, H. W. Barkema, and J. De Buck. 2020. Genomic analysis of bovine Staphylococcus aureus isolates from milk to elucidate diversity and determine the distributions of antimicrobial and virulence genes and their association with mastitis. J. Clin. Microbiol. 5:e00063-20. https://doi.org/10 $.1128 / \mathrm{mSystems} .00063-20$.

O'Riordan, K., and J. C. Lee. 2004. Staphylococcus aureus capsular polysaccharides. Clin. Microbiol. Rev. 17:218-234. https://doi .org/10.1128/CMR.17.1.218-234.2004.

Otto, M. 2013. Staphylococcal infections: Mechanisms of biofilm maturation and detachment as critical determinants of pathogenicity. Annu. Rev. Med. 64:175-188. https://doi.org/10.1146/annurev -med-042711-140023.

Oviedo-Boyso, J., J. J. Valdez-Alarcón, M. Cajero-Juárez, A. OchoaZarzosa, J. E. López-Meza, A. Bravo-Patiño, and V. M. BaizabalAguirre. 2007. Innate immune response of bovine mammary gland to pathogenic bacteria responsible for mastitis. J. Infect. 54:399409. https://doi.org/10.1016/j.jinf.2006.06.010.

Park, S., D. Jung, B. O'Brien, J. Ruffini, F. Dussault, A. Dubé-Duquette, E. Demontier, J.-F. Lucier, F. Malouin, S. Dufour, and J. Ronholm. 2020. Comparative genomic study of Staphylococcus aureus: Lessons from its gene contents. Mastitis Network Annual Meeting, Montreal, QC, Canada. McGill. https://jenniferronholm .wixsite.com/laboratory/presentations.

Pereyra, E. A. L., S. C. Sacco, A. Duré, C. Baravalle, M. S. Renna, C. S. Andreotti, S. Monecke, L. F. Calvinho, and B. E. Dallard. 2017. Immune response of Staphylococcus aureus strains in a mouse mastitis model is linked to adaptive capacity and genotypic profiles. Vet. Microbiol. 204:64-76. https://doi.org/10.1016/j.vetmic 2017.04.009.

Pichette-Jolette, S., G. Millette, E. Demontier, D. Bran-Barrera, M. Cyrenne, C. Ster, D. Haine, G. Keefe, F. Malouin, and J. P. Roy. 2019. Partial prediction of the duration and the clinical status of Staphylococcus aureus bovine intramammary infections based on the phenotypic and genotypic analysis of isolates. Vet. Microbiol. 228:188-195. https://doi.org/10.1016/j.vetmic.2018.11.024.

Proctor, R. A., C. von Eiff, B. C. Kahl, K. Becker, P. McNamara, M. Herrmann, and G. Peters. 2006. Small colony variants: A pathogenic form of bacteria that facilitates persistent and recurrent infections. Nat. Rev. Microbiol. 4:295-305. https://doi.org/10.1038/ nrmicro1384.

Rainard, P., G. Foucras, J. R. Fitzgerald, J. L. Watts, G. Koop, and J. R. Middleton. 2018. Knowledge gaps and research priorities in Staphylococcus aureus mastitis control. Transbound. Emerg. Dis. 65:149-165. https://doi.org/10.1111/tbed.12698. 
Reyher, K. K., S. Dufour, H. W. Barkema, L. Des Côteaux, T. J. DeVries, I. R. Dohoo, G. P. Keefe, J.-P. Roy, and D. T. Scholl. 2011. The National Cohort of Dairy Farms - A data collection platform for mastitis research in Canada. J. Dairy Sci. 94:16161626. https://doi.org/10.3168/jds.2010-3180.

Rodriguez, M., P. G. Hogan, S. W. Satola, E. Crispell, T. Wylie, H. Gao, E. Sodergren, G. M. Weinstock, C.-A. D. Burnham, and S. A. Fritz. 2015. Discriminatory indices of typing methods for epidemiologic analysis of contemporary Staphylococcus aureus strains. Medicine (Baltimore) 94:e1534. https://doi.org/10.1097/ MD.0000000000001534.

Ruiz, R., L. O. Tedeschi, and A. Sepúlveda. 2017. Investigation of the effect of pegbovigrastim on some periparturient immune disorders and performance in Mexican dairy herds. J. Dairy Sci. 100:33053317. https://doi.org/10.3168/jds.2016-12003.

Said, K. B., J. Ismail, J. Campbell, M. R. Mulvey, A.-M. Bourgault, S. Messier, and X. Zhao. 2010. Regional profiling for determination of genotype diversity of mastitis-specific Staphylococcus aureus lineage in Canada by use of clumping factor A, pulsed-field gel electrophoresis, and spa typing. J. Clin. Microbiol. 48:375-386. https: //doi.org/10.1128/JCM.01768-09.

Sharp, J. A., C. G. Echague, P. S. Hair, M. D. Ward, J. O. Nyalwidhe, J. A. Geoghegan, T. J. Foster, and K. M. Cunnion. 2012. Staphylococcus aureus surface protein SdrE binds complement regulator factor $\mathrm{H}$ as an immune evasion tactic. PLoS One 7:e38407. https:/ /doi.org/10.1371/journal.pone.0038407.

Snel, G. G. M., S. Monecke, R. Ehricht, and R. Piccinini. 2015. Molecular characteristics of bap-positive Staphylococcus aureus strains from dairy cow mastitis. J. Dairy Res. 82:312-316. https://doi .org/10.1017/S0022029915000199.

Soe, Y. M., S. Bedoui, T. P. Stinear, and A. Hachani. 2021. Intracellular Staphylococcus aureus and host cell death. Cell. Microbiol. 23:e13317. https://doi.org/10.1111/cmi.13317.

Ster, C., V. Lebeau, J. Leclerc, A. Fugère, K. A. Veh, J.-P. Roy, and F. Malouin. 2017. In vitro antibiotic susceptibility and biofilm production of Staphylococcus aureus isolates recovered from bovine intramammary infections that persisted or not following extended therapies with cephapirin, pirlimycin or ceftiofur. Vet. Res. 48:56. https://doi.org/10.1186/s13567-017-0463-0.

Taglialegna, A., I. Lasa, and J. Valle. 2016. Amyloid structures as biofilm matrix scaffolds. J. Bacteriol. 198:2579-2588. https://doi .org/10.1128/JB.00122-16.

Trinchieri, G. 1997. Cytokines acting on or secreted by macrophages during intracellular infection (IL-10, IL-12, IFN- $\gamma$ ). Curr. Opin. Immunol. 9:17-23. https://doi.org/10.1016/S0952-7915(97)80154 -9 .

Tristan, A., L. Ying, M. Bes, J. Etienne, F. Vandenesch, and G. Lina. 2003. Use of multiplex PCR to identify Staphylococcus aureus ad- hesins involved in human hematogenous infections. J. Clin. Microbiol. 41:4465-4467. https://doi.org/10.1128/JCM.41.9.4465-4467 2003 .

Tuchscherr, L., V. Heitmann, M. Hussain, D. Viemann, J. Roth, C. von Eiff, G. Peters, K. Becker, and B. Löffler. 2010. Staphylococcus aureus small-colony variants are adapted phenotypes for intracellular persistence. J. Infect. Dis. 202:1031-1040. https://doi.org/10 $.1086 / 656047$.

Tung, H., B. Guss, U. Hellman, L. Persson, K. Rubin, and C. Rydén. 2000. A bone sialoprotein-binding protein from Staphylococcus aureus: a member of the staphylococcal Sdr family. Biochem. J. 345:611-619. https://doi.org/10.1042/bj3450611.

Veh, K. A., R. C. Klein, C. Ster, G. Keefe, P. Lacasse, D. Scholl, J.P. Roy, D. Haine, S. Dufour, B. G. Talbot, A. O. B. Ribon, and F. Malouin. 2015. Genotypic and phenotypic characterization of Staphylococcus aureus causing persistent and nonpersistent subclinical bovine intramammary infections during lactation or the dry period. J. Dairy Sci. 98:155-168. https://doi.org/10.3168/jds .2014-8044.

Vrieling, M., E. M. Boerhout, G. F. van Wigcheren, K. J. Koymans, T. G. Mols-Vorstermans, C. J. C. de Haas, P. C. Aerts, I. J. J. M. Daemen, K. P. M. van Kessel, A. P. Koets, V. P. M. G. Rutten, P. J. M. Nuijten, J. A. G. van Strijp, and L. Benedictus. 2016. LukMF' is the major secreted leukocidin of bovine Staphylococcus aureus and is produced in vivo during bovine mastitis. Sci. Rep. 6:37759. https://doi.org/10.1038/srep37759.

Wilson, G. J., S. W. Tuffs, B.A. Wee, K. S. Seo, N. Park, T. Connelley, C. M. Guinane, W. I. Morrison, and J. R. Fitzgerald. 2018. Bovine Staphylococcus aureus superantigens stimulate the entire $\mathrm{T}$ cell repertoire of cattle. Infect. Immun. 86:e00505-18. https://doi.org/ 10.1128/IAI.00505-18.

Xue, H., H. Lu, and X. Zhao. 2011. Sequence diversities of serineaspartate repeat genes among Staphylococcus aureus isolates from different hosts presumably by horizontal gene transfer. PLoS One 6:e20332. https://doi.org/10.1371/journal.pone.0020332.

\section{ORCIDS}

Elodie Demontier (ํ) https://orcid.org/0000-0002-2675-1537 Céline Ster ํ https://orcid.org/0000-0002-1633-9696

Jennifer Ronholm @ https://orcid.org/0000-0002-1376-6131

Simon Dufour @ https://orcid.org/0000-0001-6418-0424

Jean-Philippe Roy 누 https://orcid.org/0000-0002-0444-2303

François Malouin (1) https://orcid.org/0000-0001-5031-345X 